[Frontiers in Bioscience S3, 372-384, January 1, 2011]

\title{
Roles of phytochemicals in amino acid nutrition
}

\author{
Xiangfeng Kong ${ }^{1}$, Guoyao $\mathrm{Wu}^{1-3}$, Yinlong Yin ${ }^{1}$
}

${ }^{1}$ Hunan Engineering and Research Center of Animal and Poultry Science and Key Laboratory for Agro-ecological Processes in Subtropical Region, Institute of Subtropical Agriculture, the Chinese Academy of Sciences, Changsha, Hunan, China 410125, ${ }^{2}$ Department of Animal Science, Texas A\&M University, College Station, TX, USA 77843, ${ }^{3}$ State Key Laboratory of Animal Nutrition, China Agricultural University, Beijing, China 100193

\section{TABLE OF CONTENTS}

\section{Abstract}

2. Introduction

3. Amino Acid composition in typical Chinese herbs

4. Effects of dietary supplementation with Chinese herbal powder on ileal digestibilities of amino acids in weaned piglets

5. Effects of dietary supplementation with Acanthopanax senticosus extracts on ileal digestibilities of amino acids in weaned piglets

6. Effects of dietary supplementation with Astragalus polysaccharide on ileal digestibilities of amino acids in weaned piglets

7. Effects of dietary supplementation with glycyrrhetinic acid on endogenous arginine provision in early-weaned piglets

8. Effects of steroidal saponin from Yucca schidigera extract (BIOPOWDER) on intestinal arginase activity

9. Summary and perspective

10. Acknowledgements

11. References

\section{ABSTRACT}

Chinese herbal medicine (CHM) is often used as dietary supplements to maintain good health in animals and humans. Here, we review the current knowledge about effects of CHM (including ultra-fine Chinese herbal powder, Acanthopanax senticosus extracts, Astragalus polysaccharide, and glycyrrhetinic acid) as dietary additives on physiological and biochemical parameters in pigs, chickens and rodents. Additionally, we propose possible mechanisms for the beneficial effects of CHM on the animals. These mechanisms include (a) increased digestion and absorption of dietary amino acids; (b) altered catabolism of amino acids in the small intestine and other tissues; (c) enhanced synthesis of functional amino acids (e.g., arginine, glutamine and proline) and polyamines; and (d) improved metabolic control of nutrient utilization through cell signaling. Notably, some phytochemicals and glucocorticoids share similarities in structure and physiological actions. New research findings provide a scientific and clinical basis for the use of CHM to improve well-being in livestock species and poultry, while enhancing the efficiency of protein accretion. Results obtained from animal studies also have important implications for human nutrition and health.

\section{INTRODUCTION}

Chinese traditional veterinary medicine (CTVM) has been practiced for several thousand years on the basis of a five-element (phase) theory and the principle that every healthy organism is in a Yin-Yang balance (1). Balance is considered to be a complex interplay between body and mind, which is reflected at all levels, ranging from the biochemical component perspective to the energetic system control of the physical body. Chinese herbal medicine (CHM) is the foundation of CTVM, in which more than $80 \%$ constituents of preparations are derived from plants (2). $\mathrm{CHM}$ is often used to maintain good health rather than to cure illness, much in the same way as amino acid (AA), vitamin or mineral supplements are used in Western countries (3). Based on a belief that CHM is natural, safe, and of relatively low cost, global use of $\mathrm{CHM}$ as herbal supplements continuously increases. In recent years, animal producers and veterinarians have begun to use the herbs to improve health and growth performance of pigs and poultry (4). Here, we review the current state of knowledge about the effects of CHM (including ultra-fine Chinese herbal powder, Acanthopanax senticosus extracts, Astragalus polysaccharide, and glycyrrhetinic acid) on physiological parameters and their use as growth and health 
Table 1. Resources of seventeen Chinese herbal medicines

\begin{tabular}{|c|c|c|c|}
\hline Chinese herbal medicines & Chinese name & Process method & Place of production \\
\hline Polyporus $(P P)$ & Zhuling & Crude & Shanxi \\
\hline Poria $(P O)$ & Fuling & Crude & Hunan \\
\hline Radix glycyrrhizae $(R G)$ & Gancao & Crude & NeiMenggu \\
\hline Radix angelicae sinensis (RAS) & Danggui & Crude & Gansu \\
\hline Radix ginseng (RGS) & Renshen & Crude & Jilin \\
\hline Gold Theragran (GT) & Jiaogulan & Crude & Hunan \\
\hline Radix polygoni multiflori (RPM) & Heshouwu & Seaming & Hubei \\
\hline Semen Allii Tuberosi (SAT) & Jiucaizi & Crude & Hunan \\
\hline Fructus crataegi $(F C)$ & Shanzha & Crude & Hebei \\
\hline Radix paeoniae alba (RPA) & Baishao & Crude & Anhui \\
\hline Acanthopanax senticosus $(A S)$ & Ciwujia & Crude & Sichuan \\
\hline Rhizoma atractylodis macrocephalae (RAM) & Baishu & Rinse & Zhejiang \\
\hline Astragalus membranaceus $(A M)$ & Huangqi & Crude & Liaoning \\
\hline Radix codonopsis $(R C)$ & Dangshen & Crude & Gansu \\
\hline Salvia miltiorrhiza (SM) & Danshen & Crude & Sichuan \\
\hline Radix rehmanniae preparata $(R R P)$ & Shudihuang & Cooked & Henan \\
\hline Rhizoma dioscoreae $(R D)$ & Shanyao & Crude & Hunan \\
\hline
\end{tabular}

promoters. We also propose the underlying mechanisms for the beneficial effects of CHM on the basis of studies with swine, an excellent animal model for studying human nutrition and metabolism (5-9).

\section{AMINO ACIDS COMPOSITION IN TYPICAL CHINESE HERBS}

Amino acids (AA) play important roles in gene expression, protein synthesis, cell signaling, metabolism, physiology, and health (10-13). Therefore, as an initial step to define the mechanisms responsible for the beneficial effects of typical Chinese herbs on health and growth performance of animals, we determined the contents of AA in seventeen Chinese herbs (Table 1). The herbs included Polyporus, Radix glycyrrhizae, Radix angelicae sinensis, Radixginseng, Gold Theragran, Radix polygoni multiflori, Semen Allii Tuberosi, Radix paeoniae alba, Rhizoma atractylodis macrocephalae, Astragalus membranaceus, Radix codonopsis, Radix rehmanniae preparata, Rhizoma dioscoreae, Radix Salvia miltiorrhizae, Poria, Fructus crataegi and Acanthopanax senticosus. Results are expressed on the dry matter (DM) basis. Percentages (\%) of DM in Radix glycyrrhizae (95.1) and Astragalus membranaceus (93.6) were highest, followed by Fructus crataegi (93.0), Radix paeoniae alba (92.9) and Radix angelicae sinensis (92.5). The content (\%) of crude protein was highest in Semen Allii Tuberosi (26.4), followed by Radix codonopsis (16.7), Astragalus membranaceus (16.3) and Gold Theragran (16.0). The content (\%) of total AA in Semen Allii Tuberosi (17.2) was highest, followed by Astragalus membranaceus (11.0), Gold Theragran (8.9) and Radix angelicae sinensis (8.2). Aromatic AA (Phe + Tyr) were most abundant (\% of ingredient) in Semen Allii Tuberosi (1.2) and Astragalus membranaceus (0.9); branched-chain AA (Leu + Ile + Val $)$ in Semen Allii Tuberosi (2.7) and Polyporus (2.1); small neutral AA (Ala + Gly) in Semen Allii Tuberosi (1.6), Gold Theragran (1.1), and Astragalus membranaceus (1.0); acidic AA + Cys + Pro (Asp + Glu) in Semen Allii Tuberosi (6.4), Astragalus membranaceus (4.3) and Radix glycyrrhizae (3.6); basic AA (His + Lys + Arg) in Semen Allii Tuberosi (3.5), Radix angelicae sinensis(3.0), and Radix ginseng (2.5); as well as hydroxy AA (Thr + Ser) in Semen Allii Tuberosi (1.6), Gold
Theragran (1.0), and Astragalus membranaceus (0.9) (Table 2). The composition of AA in the Chinese herbs is largely similar to that in feeds of plant origin, which indicate that typical Chinese herbs are not unique in the composition of protein-precursor AA among plants. Other components in the herbs are likely major active components that beneficially regulate intestinal barrier integrity, absorption and metabolism of nutrients (including AA), immune function, health, and protein synthesis in animals $(14,15)$.

\section{EFFECTS OF DIETARY SUPPLEMENTATION WITH ULTRA-FINE CHINESE HERBAL POWDER ON ILEAL DIGESTIBILITIES OF AMINO ACIDS IN WEANED PIGLETS}

Our previous studies have demonstrated that the ultra-fine Chinese herbal (UCH) powder is safe and effective in preventing intestinal dysfunction, improving growth performance (16), as well as exerting beneficial effects on immune responses (17) and gut microbiota development (18) in weanling piglets. However, the underlying mechanisms are largely unknown. Considering that most of composition herbs in the UCH powder are commonly employed for treatment of dyspepsia and poor appetite, and because AA are not only building blocks for protein synthesis but also serve as regulators of key metabolic pathways (19-22) and the immune response (23), we hypothesized that the UCH powder may affect the digestion of dietary protein, the intestinal absorption of AA, and circulating levels of AA in weanling piglets.

There have been published studies to determine effects of the herbal powder as a dietary additive on serum concentrations and apparent ileal digestibilities (AID) of AA in piglets weaned at 21 days of age $(16,24)$. Dietary supplementation with the herbal powder $(2 \mathrm{~g} / \mathrm{kg})$ increased $(P<0.05)$ serum concentrations and AID of most AA by $10 \%-50 \%$ and $10 \%-16 \%$, respectively (Table 3 and 4 ). As an indicator of improved intestinal function, AID values of calcium were also enhanced in piglets supplemented with the herbal powder. Dietary supplementation of colistin (an antibiotic as a positive control) increased serum concentrations and AID values of some AA by $8 \%-44 \%$ 
Table 2. The contents of amino acids in seventeen Chinese herbal medicines (\%)

\begin{tabular}{|c|c|c|c|c|c|c|c|c|c|c|c|c|c|c|c|c|c|c|}
\hline \multicolumn{2}{|c|}{ Amino acids (AA) } & PP & PO & RG & RAS & RGS & GT & RPM & SAT & FC & RPA & AS & RAM & RA & $\mathbf{R C}$ & SM & RRP & RD \\
\hline \multirow[t]{2}{*}{ Aromatic } & $\begin{array}{l}\text { Phenylalanine } \\
\end{array}$ & 0.16 & 0.05 & 0.35 & 0.33 & 0.28 & 0.57 & 0.02 & 0.52 & 0.11 & 0.58 & 0.18 & 0.81 & 0.24 & 0.83 & 0.09 & 0.23 & 0.78 \\
\hline & $\begin{array}{l}\text { Tyrosine } \\
\end{array}$ & 0.02 & 0.01 & 0.11 & 0.08 & 0.07 & 0.27 & & & 0.04 & & 0.03 & 0.10 & 0.04 & & 0.02 & 0.12 & 0.42 \\
\hline \multirow{3}{*}{$\begin{array}{l}\text { Branched } \\
\text { Chain }\end{array}$} & Leucine & 0.28 & 0.06 & 0.49 & 0.55 & 0.44 & 0.86 & 0.02 & 0.36 & 0.17 & 0.36 & 0.23 & 0.69 & 0.32 & 0.65 & 0.15 & 0.52 & 1.15 \\
\hline & Isoleucine & 0.19 & 0.03 & 0.28 & 0.30 & 0.22 & 0.46 & 0.01 & 0.14 & 0.10 & 0.13 & 0.14 & 0.38 & 0.19 & 0.28 & 0.09 & 0.21 & 0.62 \\
\hline & $\begin{array}{l}\text { Valine } \\
\end{array}$ & 1.59 & 0.02 & 0.41 & 0.42 & 0.25 & 0.56 & 0.01 & 0.16 & 0.16 & 0.14 & 0.18 & 0.53 & 0.26 & 0.30 & 0.11 & 0.41 & 0.88 \\
\hline \multirow{2}{*}{$\begin{array}{l}\text { Small } \\
\text { Neutral }\end{array}$} & Alanine & 0.19 & 0.05 & 0.32 & 0.42 & 0.30 & 0.53 & 0.01 & 0.27 & 0.10 & 0.26 & 0.17 & 0.58 & 0.26 & 0.48 & 0.08 & 0.23 & 0.81 \\
\hline & Glycine & 0.23 & 0.04 & 0.29 & 0.38 & 0.19 & 0.54 & 0.02 & 0.2 & 0.10 & 0.13 & 0.15 & 0.46 & 0.23 & 0.31 & 0.09 & 0.16 & 0.79 \\
\hline \multirow{4}{*}{$\begin{array}{l}\text { Acidic AA } \\
+ \text { Cysteine } \\
+ \text { Proline }\end{array}$} & Aspartate $^{\top}$ & 0.62 & & 1.95 & 0.71 & 0.70 & 1.09 & 0.02 & 0.37 & & 0.33 & 0.70 & 1.76 & 0.45 & 0.71 & & 0.45 & 1.44 \\
\hline & Glutamate $^{2}$ & 0.38 & 0.08 & 0.74 & 1.11 & 1.57 & 1.24 & 0.05 & 0.56 & 0.39 & 0.44 & 0.43 & 1.46 & 1.03 & 1.17 & 0.75 & 1.17 & 4.23 \\
\hline & $\begin{array}{l}\text { Cysteine } \\
\end{array}$ & 0.05 & & 0.01 & 0.09 & 0.02 & 0.09 & & 0.26 & 0.01 & 0.32 & 0.01 & 0.34 & 0.05 & 0.40 & & 0.02 & 0.27 \\
\hline & Proline & 0.11 & 0.01 & 0.94 & 0.20 & 0.15 & 0.33 & 0.01 & & 0.08 & & 0.32 & 0.73 & 0.25 & 0.23 & 0.02 & & 0.42 \\
\hline \multirow[t]{3}{*}{ Basic } & Histidine & 0.09 & 0.01 & 0.27 & 0.16 & 0.13 & 0.21 & 0.01 & 0.10 & 0.06 & 0.05 & 0.09 & 0.36 & 0.11 & 0.19 & 0.03 & 0.14 & 0.41 \\
\hline & Lysine & 0.14 & 0.03 & 0.38 & 0.52 & 0.36 & 0.57 & 0.01 & 0.54 & 0.22 & 0.21 & 0.20 & 1.15 & 0.22 & 0.40 & 0.00 & 0.17 & 1.17 \\
\hline & Arginine & 0.19 & 0.04 & 0.74 & 2.26 & 1.96 & 0.58 & 0.03 & 0.15 & 0.50 & 0.35 & 1.16 & 0.68 & 1.20 & 0.86 & 0.05 & 0.39 & 1.94 \\
\hline \multirow[t]{2}{*}{ Hydroxy } & Threonine & 0.21 & 0.01 & 0.30 & 0.33 & 0.25 & 0.44 & 0.02 & 0.17 & 0.03 & 0.15 & 0.13 & 0.42 & 0.17 & 0.30 & 0.02 & 0.10 & 0.61 \\
\hline & Serine & 0.23 & - & 0.42 & 0.34 & 0.19 & 0.54 & 0.02 & 0.21 & 0.06 & 0.20 & 0.16 & 0.50 & 0.22 & 0.36 & - & 0.20 & 1.00 \\
\hline \multicolumn{2}{|c|}{ Methionine } & - & 0.03 & - & - & 0.01 & 0.01 & - & 0.03 & 0.01 & 0.03 & - & 0.04 & - & 0.03 & 0.01 & 0.06 & 0.28 \\
\hline & 0.18 & 0.06 & 0.46 & 0.41 & 0.35 & 0.84 & 0.02 & 1.20 & 0.52 & 0.15 & 0.58 & 0.22 & 0.90 & 0.28 & 0.83 & 0.12 & 0.35 \\
\hline & 2.07 & 0.11 & 1.18 & 1.27 & 0.91 & 1.87 & 0.04 & 2.65 & 0.66 & 0.43 & 0.63 & 0.54 & 1.60 & 0.77 & 1.23 & 0.35 & 1.14 \\
\hline & & 0.42 & 0.09 & 0.62 & 0.80 & 0.49 & 1.07 & 0.04 & 1.61 & 0.47 & 0.20 & 0.39 & 0.33 & 1.03 & 0.49 & 0.79 & 0.17 & 0.39 \\
\hline \multicolumn{2}{|c|}{$\begin{array}{l}\text { Small and neutral AA } \\
\text { Acidic AA +Cysteine+Proline }\end{array}$} & 1.16 & 0.09 & 3.64 & 2.11 & 2.44 & 2.74 & 0.08 & 6.36 & 1.19 & 0.48 & 1.09 & 1.46 & 4.29 & 1.78 & 2.51 & 0.76 & 1.63 \\
\hline \multicolumn{2}{|c|}{ Basic AA } & 0.42 & 0.08 & 1.38 & 2.95 & 2.45 & 1.35 & 0.05 & 3.52 & 0.79 & 0.78 & 0.61 & 1.46 & 2.19 & 1.52 & 1.45 & 0.08 & 0.70 \\
\hline \multicolumn{2}{|c|}{ Hydroxy AA } & 0.44 & 0.01 & 0.73 & 0.68 & 0.44 & 0.98 & 0.04 & 1.61 & 0.38 & 0.09 & 0.35 & 0.30 & 0.92 & 0.39 & 0.65 & 0.02 & 0.30 \\
\hline \multicolumn{2}{|l|}{ Total AA } & 4.67 & 0.46 & 8.00 & 8.21 & 7.09 & 8.87 & 0.25 & 17.22 & 4.04 & 2.13 & 3.68 & 4.29 & 10.96 & 5.22 & 7.49 & 1.50 & 4.57 \\
\hline
\end{tabular}

${ }^{1}$ Including aspartate plus asparagine. ${ }^{2}$ Including glutamate plus glutamine. Adapted from $\mathrm{Wu}$ et al. (15). Values are means of 6 measurements.

Table 3. Serum concentrations $(\mu \mathrm{g} / \mathrm{mL})$ of amino acids in weaned piglets on $\mathrm{d} 7-28$ after initiation of dietary supplementation with ultra-fine Chinese herbal powder (UCHP)

\begin{tabular}{|c|c|c|c|c|c|c|c|c|c|}
\hline \multirow{3}{*}{ Item } & \multicolumn{9}{|c|}{ Day after initiation of dietary supplementation } \\
\hline & \multicolumn{3}{|l|}{ Day 7} & \multicolumn{3}{|l|}{ Day 14} & \multicolumn{3}{|l|}{ Day 28} \\
\hline & UCHP & Colistin & None & UCHP & Colistin & None & UCHP & Colistin & None \\
\hline Alanine & $92 \pm 5.7$ & $98 \pm 13.5$ & $99 \pm 11.5$ & $99 \pm 10.3^{\mathrm{a}}$ & $88 \pm 8.2^{\mathrm{ab}}$ & $76 \pm 9.2^{b}$ & $98 \pm 14.3^{\mathrm{a}}$ & $91 \pm 8.4^{\mathrm{a}}$ & $66 \pm 7.2^{b}$ \\
\hline Arginine & $44 \pm 10.8$ & $47 \pm 4.5$ & $40 \pm 3.8$ & $43 \pm 2.4$ & $39 \pm 10.6$ & $35 \pm 4.9$ & $47 \pm 14.5$ & $47 \pm 5.9$ & $42 \pm 4.7$ \\
\hline Aspartate $^{1}$ & $10 \pm 0.5^{\mathrm{a}}$ & $9.7 \pm 1.6^{\mathrm{a}}$ & $6.9 \pm 2.0^{b}$ & $10 \pm 0.5^{\mathrm{a}}$ & $8.0 \pm 1.2^{b}$ & $7.1 \pm 1.0^{\mathrm{b}}$ & $12 \pm 2.7$ & $12 \pm 0.8$ & $9.8 \pm 1.5$ \\
\hline Cysteine & $3.8 \pm 0.4^{\mathrm{b}}$ & $3.5 \pm 0.4^{\mathrm{b}}$ & $4.9 \pm 0.2^{\mathrm{a}}$ & $4.5 \pm 0.6$ & $4.9 \pm 0.7$ & $3.9 \pm 0.8$ & $3.9 \pm 0.7$ & $3.4 \pm 0.3$ & $3.7 \pm 0.9$ \\
\hline Glutamate $^{2}$ & $110 \pm 9.0^{b}$ & $136 \pm 11.0^{\mathrm{a}}$ & $117 \pm 14.0^{b}$ & $115 \pm 14^{\mathrm{a}}$ & $111 \pm 14^{\mathrm{a}}$ & $77.0 \pm 4.0^{\mathrm{b}}$ & $122 \pm 22$ & $116 \pm 13$ & $107 \pm 13$ \\
\hline Glycine & $89 \pm 6.0^{b}$ & $102 \pm 15.0^{b}$ & $129 \pm 17.0^{\mathrm{a}}$ & $113 \pm 13$ & $96 \pm 10$ & $100 \pm 13$ & $108 \pm 17$ & $120 \pm 11$ & $97 \pm 19$ \\
\hline Isoleucine & $23 \pm 3.0$ & $24 \pm 1.6$ & $20 \pm 2.5$ & $22 \pm 2.2$ & $22 \pm 3.3$ & $19 \pm 3.5$ & $23 \pm 2.3^{\mathrm{a}}$ & $23 \pm 2.6^{\mathrm{a}}$ & $17 \pm 1.6^{b}$ \\
\hline Leucine & $40 \pm 6.7$ & $40 \pm 0.8$ & $38 \pm 5.5$ & $32 \pm 3.1$ & $35 \pm 3.5$ & $31 \pm 8.2$ & $40 \pm 2.9^{\mathrm{a}}$ & $39 \pm 4.1^{\mathrm{a}}$ & $27 \pm 2.6^{b}$ \\
\hline Lysine & $66 \pm 4.5^{b}$ & $54 \pm 6.1^{\mathrm{c}}$ & $79 \pm 8.3^{\mathrm{a}}$ & $45 \pm 3.6$ & $50 \pm 8.8$ & $43 \pm 1.4$ & $56 \pm 7.3^{\mathrm{a}}$ & $49 \pm 5.5^{\mathrm{a}}$ & $38 \pm 3.6^{b}$ \\
\hline Methionine & $9.9 \pm 2.3^{b}$ & $13 \pm 1.8^{\mathrm{a}}$ & $12 \pm 1.0^{\mathrm{ab}}$ & $12 \pm 0.8^{\mathrm{a}}$ & $7.7 \pm 0.7^{b}$ & $8.4 \pm 2.5^{b}$ & $12 \pm 1.6^{\mathrm{a}}$ & $10 \pm 1.1^{\mathrm{ab}}$ & $8.1 \pm 2.0^{b}$ \\
\hline Phenylalanine & $30 \pm 1.4^{\mathrm{a}}$ & $24 \pm 1.3^{b}$ & $25 \pm 1.8^{b}$ & $25 \pm 1.8$ & $25 \pm 4.6$ & $24 \pm 2.7$ & $26 \pm 4.9^{\mathrm{a}}$ & $24 \pm 2.5^{\mathrm{ab}}$ & $21 \pm 2.2^{b}$ \\
\hline Serine & $27 \pm 4.9$ & $25 \pm 4.0$ & $27 \pm 3.1$ & $28 \pm 2.7^{\mathrm{a}}$ & $25 \pm 2.7^{\mathrm{ab}}$ & $23 \pm 2.7^{b}$ & $25 \pm 2.7^{\mathrm{ab}}$ & $26 \pm 3.4^{\mathrm{a}}$ & $20 \pm 3.4^{b}$ \\
\hline Threonine & $70 \pm 14.9$ & $50 \pm 18.8$ & $55 \pm 6.7$ & $56 \pm 3.3^{\mathrm{a}}$ & $40 \pm 4.6^{\mathrm{b}}$ & $44 \pm 4.9^{b}$ & $67 \pm 14.4^{\mathrm{a}}$ & $39 \pm 5.5^{\mathrm{b}}$ & $52 \pm 15.9^{\mathrm{ab}}$ \\
\hline Tyrosine & $31 \pm 2.9^{\mathrm{a}}$ & $22 \pm 4.5^{b}$ & $28 \pm 2.9^{\mathrm{a}}$ & $27 \pm 2.6$ & $29 \pm 4.3$ & $32 \pm 6.8$ & $31 \pm 9.2^{\mathrm{ab}}$ & $38 \pm 4.5^{\mathrm{a}}$ & $28 \pm 4.9^{b}$ \\
\hline
\end{tabular}

Data are expressed as means $\pm \mathrm{SEM}, \mathrm{n}=5$. Means with different superscripts in a row differ $(P<0.05)$. ${ }^{1}$ Including aspartate plus asparagine. ${ }^{2}$ Including glutamate plus glutamine.

Sixty Duroc $\times$ Landrace $\times$ Yorkshire piglets weaned at 21 days of age were randomly assigned to one of three treatments, representing supplementation with 0 or $2 \mathrm{~g} / \mathrm{kg}$ of the powder, or $0.2 \mathrm{~g} / \mathrm{kg}$ of colistin (an antibiotic) to corn- and soybean meal-based diets. Blood samples from five piglets per group were collected on days 7, 14 and 28 to determine serum concentrations of free amino acids. Adapted from Kong et al. (16).

Table 4. Apparent ileal digestibilitis ( ) of amino acids in weaned piglets on d 7-28 after initiation of dietary supplementation with ultra-fine Chinese herbal powder (UCHP)

\begin{tabular}{|c|c|c|c|c|c|c|c|c|c|}
\hline \multirow{3}{*}{ Item } & \multicolumn{9}{|c|}{ Day after initiation of dietary supplementation } \\
\hline & \multicolumn{3}{|c|}{ Day 7} & \multicolumn{3}{|l|}{ Day 14} & \multicolumn{3}{|l|}{ Day 28} \\
\hline & UCHP & Colistin & None & UCHP & Colistin & None & UCHP & Colistin & None \\
\hline Alanine & $70 \pm 2.4$ & $73 \pm 1.2$ & $71 \pm 1.4$ & $78 \pm 2.4$ & $77 \pm 3.4$ & $77 \pm 2.4$ & $82 \pm 3.1$ & $82 \pm 3.9$ & $80 \pm 4.0$ \\
\hline Arginine & $70 \pm 2.0^{\mathrm{a}}$ & $65 \pm 1.3^{\mathrm{b}}$ & $64 \pm 2.0^{\mathrm{b}}$ & $82 \pm 3.1^{\mathrm{a}}$ & $83 \pm 2.1^{\mathrm{a}}$ & $76 \pm 2.1^{\mathrm{b}}$ & $88 \pm 2.2^{\mathrm{a}}$ & $80 \pm 2.1^{\mathrm{b}}$ & $81 \pm 3.1^{\mathrm{b}}$ \\
\hline Aspartate $^{1}$ & $72 \pm 2.6$ & $73 \pm 2.0$ & $70 \pm 3.7$ & $80 \pm 3.5$ & $81 \pm 3.4$ & $80 \pm 3.3$ & $88 \pm 1.2^{\mathrm{a}}$ & $87 \pm 2.0^{\mathrm{a}}$ & $76 \pm 2.2^{b}$ \\
\hline Cysteine & $63 \pm 0.0$ & $65 \pm 2.1$ & $62 \pm 2.0$ & $77 \pm 3.1$ & $76 \pm 3.0$ & $74 \pm 3.1$ & $80 \pm 2.2^{\mathrm{a}}$ & $82 \pm 2.3^{\mathrm{a}}$ & $75 \pm 2.3^{b}$ \\
\hline Glutamate $^{2}$ & $75 \pm 1.9$ & $75 \pm 1.6$ & $73 \pm 1.9$ & $85 \pm 2.7^{\mathrm{a}}$ & $84 \pm 2.5^{\mathrm{a}}$ & $79 \pm 2.4^{b}$ & $90 \pm 1.6$ & $89 \pm 3.2$ & $90 \pm 3.4$ \\
\hline Glycine & $71 \pm 2.4$ & $71 \pm 2.3$ & $72 \pm 2.4$ & $78 \pm 2.5$ & $80 \pm 3.3$ & $77 \pm 4.4$ & $82 \pm 1.9^{\mathrm{a}}$ & $83 \pm 2.2^{\mathrm{a}}$ & $75 \pm 2.0^{b}$ \\
\hline Histidine & $64 \pm 1.3^{\mathrm{a}}$ & $65 \pm 1.1^{\mathrm{a}}$ & $60 \pm 1.1^{b}$ & $74 \pm 2.2^{\mathrm{ab}}$ & $78 \pm 2.2^{\mathrm{a}}$ & $70 \pm 2.1^{b}$ & $81 \pm 2.0^{\mathrm{a}}$ & $83 \pm 2.1^{\mathrm{a}}$ & $72 \pm 2.0^{b}$ \\
\hline Isoleucine & $70 \pm 2.2^{\mathrm{a}}$ & $70 \pm 1.1^{\mathrm{a}}$ & $65 \pm 1.5^{b}$ & $79 \pm 3.1$ & $81 \pm 3.3$ & $78 \pm 2.4$ & $83 \pm 3.2$ & $86 \pm 3.1$ & $84 \pm 4.0$ \\
\hline Leucine & $75 \pm 1.1^{\mathrm{ab}}$ & $79 \pm 2.2^{\mathrm{a}}$ & $70 \pm 3.4^{b}$ & $81 \pm 3.4^{\mathrm{a}}$ & $78 \pm 2.4^{\mathrm{ab}}$ & $76 \pm 2.2^{b}$ & $88 \pm 2.5^{\mathrm{a}}$ & $89 \pm 2.4^{\mathrm{a}}$ & $82 \pm 2.9^{b}$ \\
\hline
\end{tabular}




\begin{tabular}{|l|l|l|l|l|l|l|l|l|l|}
\hline Lysine & $66 \pm 1.4$ & $67 \pm 2.0$ & $65 \pm 2.3$ & $73 \pm 2.3^{\mathrm{a}}$ & $74 \pm 3.3^{\mathrm{a}}$ & $67 \pm 1.5^{\mathrm{b}}$ & $82 \pm 2.1^{\mathrm{a}}$ & $82 \pm 2.1^{\mathrm{a}}$ & $75 \pm 2.1^{\mathrm{b}}$ \\
\hline Methionine & $68 \pm 2.0^{\mathrm{a}}$ & $70 \pm 2.8^{\mathrm{a}}$ & $61 \pm 2.0^{\mathrm{b}}$ & $76 \pm 3.3$ & $75 \pm 4.1$ & $74 \pm 3.5$ & $80 \pm 2.2$ & $81 \pm 3.2^{\mathrm{a}}$ & $82 \pm 2.3^{\mathrm{a}}$ \\
\hline Phenylalanine & $72 \pm 1.2^{\mathrm{a}}$ & $72 \pm 1.1^{\mathrm{a}}$ & $70 \pm 0.9^{\mathrm{b}}$ & $78 \pm 2.9^{\mathrm{ab}}$ & $81 \pm 1.7^{\mathrm{a}}$ & $74 \pm 1.9^{\mathrm{b}}$ & $83 \pm 2.2^{\mathrm{a}}$ & $84 \pm 2.3^{\mathrm{a}}$ & $76 \pm 2.4^{\mathrm{b}}$ \\
\hline Serine & $66 \pm 1.9$ & $67 \pm 2.9$ & $65 \pm 3.0$ & $81 \pm 2.3^{\mathrm{a}}$ & $79 \pm 2.4^{\mathrm{ab}}$ & $75 \pm 2.3^{\mathrm{b}}$ & $89 \pm 3.2^{\mathrm{a}}$ & $90 \pm 2.2^{\mathrm{a}}$ & $83 \pm 2.1^{\mathrm{b}}$ \\
\hline Threonine & $65 \pm 2.1^{\mathrm{a}}$ & $65 \pm 2.0^{\mathrm{a}}$ & $59 \pm 2.3^{\mathrm{b}}$ & $77 \pm 2.4$ & $80 \pm 2.3$ & $78 \pm 3.7$ & $80 \pm 2.1^{\mathrm{a}}$ & $83 \pm 2.2^{\mathrm{a}}$ & $75 \pm 2.3^{\mathrm{b}}$ \\
\hline Tyrosine & $65 \pm 2.2^{\mathrm{ab}}$ & $68 \pm 2.0^{\mathrm{a}}$ & $60 \pm 2.1^{\mathrm{b}}$ & $80 \pm 3.1$ & $79 \pm 2.3$ & $81 \pm 2.4$ & $79 \pm 2.3$ & $80 \pm 3.1$ & $77 \pm 3.1$ \\
\hline Valine & $65 \pm 3.3$ & $62 \pm 2.1$ & $64 \pm 2.3$ & $83 \pm 2.2^{\mathrm{a}}$ & $84 \pm 3.4^{\mathrm{a}}$ & $78 \pm 2.2^{\mathrm{b}}$ & $79 \pm 3.1^{\mathrm{a}}$ & $80 \pm 3.2^{\mathrm{a}}$ & $74 \pm 2.3^{\mathrm{b}}$ \\
\hline
\end{tabular}

Data are expressed as means \pm SEM, $\mathrm{n}=4$. Means with different superscripts in a row differ $(P<0.05)$. ${ }^{1}$ Including aspartate plus asparagine. ${ }^{2}$ Including glutamate plus glutamine. Twelve barrows with an average initial body weight of $7.64 \mathrm{~kg}$ were randomly assigned to one of the three dietary treatments, representing supplementation with $0 \mathrm{or} 2 \mathrm{~g} / \mathrm{kg}$ of the powder, or $0.2 \mathrm{~g} / \mathrm{kg}$ of colistin (an antibiotic) to corn- and soybean meal-based diets, followed by surgical placement of a simple T-cannula at the terminal ileum. All of the diets contained $0.1 \%$ titanium oxide as a digestibility marker. The samples of terminal ileal digesta were collected on $\mathrm{d}$ 7, 14 and 28 for determining apparent ileal digestibilitis of amino acids. Adapted from Kong et al. (24).

and $10 \%-15 \%$, respectively (Table 3 and 4 ), in comparison with the non-supplemented group (24).

Amino acids regulate key metabolic pathways that are crucial for maintenance, health, and growth of animals $(19,20,25-27)$. An increase in the amounts of nutrients (particularly AA) that enter the portal vein from the small intestine can be sufficient to promote tissue protein synthesis in piglets $(13,28)$. At present, it is not clear how dietary UCH-powder supplementation can improve AA digestibilities in pigs. However, it is known that the UCH powder increased the growth of beneficial Lactobacillus (e.g. Bifidobacteria and Lactobacilli) and arrested the growth of bacterial pathogens (E. coli) (18), which suggested that the UCH powder could effectively promote the development of the normal gut microbiota and healthy intestinal environment in the weaned piglets. These Lactobacillus are also beneficial for maintaining the integrity and function of the small intestine $(29,30)$, which then promotes the absorption and transport of AA, glucose, calcium and other nutrients across the intestinal epithelium into the portal vein (31). Furthermore, the UCH powder may affect the metabolism of nutrients (particularly AA) in the lumen of the small intestine by altering the growth and metabolism of gut microbiota, therefore resulting in changes in the amounts of AA (free and protein-bound) in the ileal digesta (32). The variation of AID values for different AA may be explained by the different actions of microbes on metabolism in the lumen of the small intestine $(29,33)$. Because the underlying mechanisms are likely to multifactorial, future studies are warranted to determine the effects of active components of the UCH powder on the digestion and absorption of dietary nutrients.

The UCH powder had an average granule diameter of $30 \mu \mathrm{m}$ as a phytochemical dietary additive and was composed of Acanthopanax senticosus (AS), Astragalus membranaceus (AM), Codonopsis pilosula (COP), Crataegus pinnatifida (CRP), Salvia miltiorrhiza (SM), and chitosan $(16,17)$. As one of the major components in the herbal power, AS is highly effective in treating allergies (34), stress-induced pathophysiologic changes (35), and inflammation (36). The AS extract also enhances immune responses (37) and physiological development of the gut microflora (38) in weaned piglets. AM is known for its effect on stimulating energy metabolism, tissue regeneration, and immunity in the body (39). COP possesses immuno-modulatory, anti-oxidant, free-radical scavenging, and anti-ulcer activities, and is commonly employed for treatment of dyspepsia, poor appetite, and psychoneurosis (40). Traditionally, CRP has a strong anti-bacterial activity against pathogenic bacteria (41), whereas SM is mainly used for treatment of infectious and inflammatory diseases (42). In addition, dietary supplementation of chitosan improves growth performance, feed efficiency, and the immune response in weaned piglets (43). Our novel findings demonstrate that the herbal powder can enhance the digestibility of dietary protein and the intestinal absorption of AA into the systemic circulation in post-weaning pigs, therefore providing a new mechanism for its growth-promoting efficacy.

\section{EFFECTS OF DIETARY SUPPLEMENTATION WITH ACANTHOPANAX SENTICOSUS EXTRACTS ON ILEAL DIGESTIBILITY OF AMINO ACIDS IN WEANED PIGLETS}

Acanthopanax senticosus (AS), a tonic and sedative Chinese herb, is well known to be highly effective in treating various diseases, which include stress-induced pathophysiologic changes (35) and inflammation (36). The AS compounds include acanthosides, triterpenic saponin, polysaccharide, flavone, senticoside, organic acids, AA, vitamins and minerals (44). Saponin may be responsible for the biological activities of AS (45). Some evidence suggests that diterpenoids and phenolic substances are biologically active ingredients in Acanthopanax species (46).

Based on the above findings, we prepared the extracts of AS by decocting the dried herb in boiling distilled water $(200 \mathrm{~g} / \mathrm{L})$ for $2 \mathrm{~h}$. The AS decoction were filtered, lyophilized and kept at $4{ }^{\circ} \mathrm{C}$. The yield of extraction was $25 \%(\mathrm{w} / \mathrm{w})$. Percentages of total polysaccharides, flavone and organic acids in the AS extracts were $2.94 \%$, $0.19 \%$ and $1.04 \%$, as determined by vitriol-anthracene ketone, rutin (47) and alkalimetrictitration (48) methods, respectively. Concentrations $(\mathrm{g} / \mathrm{kg})$ of AA in the extracts, as analyzed by high-pressure liquid chromatography (HPLC, Hitachi L-8800 Auto-Analyzer, Tokyo, Japan) method (49) were: Phe 4.11; Leu 2.32; Ile 0.67; Val 0.77; Ala 2.14; Gly 1.87; Asp 2.86; Glu 4.71; Cys 2.45; His 0.41; Lys 0.95; Arg 3.78; Thr 1.30; Ser 2.47 and Met 0.28. Our previous study indicated that the AS extracts enhanced the cellular and humoral immune responses of weaned piglets by modulating the production of immunocytes, cytokines and antibodies (37). On the basis of the foregoing, we hypothesized that dietary supplementation with the AS extracts enhances the digestibility of AA in weaned piglets. 
Table 5. Serum concentrations $(\mu \mathrm{g} / \mathrm{mL})$ of amino acids in weaned piglets after initiation of dietary supplementation with Acanthopanax senticosus extracts (ASE)

\begin{tabular}{|c|c|c|c|c|c|c|c|c|c|}
\hline \multirow{3}{*}{ Item } & \multicolumn{9}{|c|}{ Day after initiation of dietary supplementation } \\
\hline & \multicolumn{3}{|c|}{ Day 7} & \multicolumn{3}{|l|}{ Day 14} & \multicolumn{3}{|l|}{ Day 28} \\
\hline & ASE & Colistin & None & ASE & Colistin & None & ASE & Colistin & None \\
\hline Alanine & $95 \pm 14.8$ & $98 \pm 13.5$ & $99 \pm 11.5$ & $104 \pm 17.3^{\mathrm{a}}$ & $88 \pm 8.2^{\mathrm{ab}}$ & $76 \pm 9.2^{b}$ & $93 \pm 6.0^{\mathrm{a}}$ & $91 \pm 8.4^{\mathrm{a}}$ & $66 \pm 7.2^{b}$ \\
\hline Arginine & $58 \pm 3.3^{\mathrm{a}}$ & $47 \pm 4.5^{\mathrm{ab}}$ & $40 \pm 3.8^{b}$ & $42 \pm 5.4$ & $39 \pm 10.6$ & $35 \pm 4.9$ & $55 \pm 6.8^{\mathrm{a}}$ & $47 \pm 5.9^{\mathrm{ab}}$ & $42 \pm 4.7^{b}$ \\
\hline Aspartate $^{1}$ & $13 \pm 1.7^{\mathrm{a}}$ & $9.7 \pm 1.59^{b}$ & $6.9 \pm 1.98^{\mathrm{c}}$ & $8.7 \pm 0.98$ & $8.0 \pm 1.20$ & $7.1 \pm 1.02$ & $10 \pm 2.7$ & $12 \pm 0.8$ & $9.8 \pm 1.47$ \\
\hline Cysteine & $5.4 \pm 0.41^{\mathrm{a}}$ & $3.5 \pm 0.37^{b}$ & $4.9 \pm 0.17^{\mathrm{a}}$ & $4.4 \pm 0.99$ & $4.9 \pm 0.65$ & $3.9 \pm 0.84$ & $3.2 \pm 0.50$ & $3.4 \pm 0.28$ & $3.7 \pm 0.94$ \\
\hline Glutamate $^{2}$ & $135 \pm 11.3^{\mathrm{a}}$ & $136 \pm 11.0^{\mathrm{a}}$ & $117 \pm 14.0^{\mathrm{b}}$ & $114 \pm 9.2^{\mathrm{a}}$ & $111 \pm 14.2^{\mathrm{a}}$ & $77 \pm 3.6^{b}$ & $120 \pm 2.7$ & $116 \pm 12.7$ & $107 \pm 13.0$ \\
\hline Glycine & $67 \pm 3.7^{\mathrm{c}}$ & $102 \pm 15.0^{b}$ & $129 \pm 17.0^{\mathrm{a}}$ & $122 \pm 1.4^{\mathrm{a}}$ & $96 \pm 9.8^{b}$ & $100 \pm 13.2^{b}$ & $116 \pm 9.0^{\mathrm{ab}}$ & $120 \pm 10.8^{\mathrm{a}}$ & $97 \pm 19.2^{b}$ \\
\hline Histidine & $19 \pm 7.6$ & $16 \pm 2.8$ & $21 \pm 3.9$ & $14 \pm 1.7$ & $13 \pm 2.5$ & $14 \pm 0.9$ & $18 \pm 0.9^{\mathrm{a}}$ & $16 \pm 1.2^{\mathrm{b}}$ & $13 \pm 2.2^{\mathrm{c}}$ \\
\hline Isoleucine & $24 \pm 2.5$ & $24 \pm 1.6$ & $20 \pm 2.5$ & $23 \pm 3.5$ & $22 \pm 3.3$ & $19 \pm 3.5$ & $24 \pm 2.9^{\mathrm{a}}$ & $23 \pm 2.6^{\mathrm{a}}$ & $17 \pm 1.6^{b}$ \\
\hline Leucine & $42 \pm 4.3$ & $40 \pm 0.8$ & $38 \pm 5.5$ & $28 \pm 4.0$ & $35 \pm 3.5$ & $31 \pm 8.2$ & $41 \pm 5.1^{\mathrm{a}}$ & $39 \pm 4.1^{\mathrm{a}}$ & $27 \pm 2.6^{\mathrm{b}}$ \\
\hline Lysine & $69 \pm 7.8^{\mathrm{a}}$ & $54 \pm 6.1^{b}$ & $79 \pm 8.3^{\mathrm{a}}$ & $51 \pm 4.8$ & $50 \pm 8.8$ & $44 \pm 1.4$ & $67 \pm 8.8^{\mathrm{a}}$ & $49 \pm 5.5^{b}$ & $38 \pm 3.6^{\mathrm{c}}$ \\
\hline Methionine & $15 \pm 3.2^{\mathrm{a}}$ & $13 \pm 1.8^{\mathrm{ab}}$ & $12 \pm 1.0^{\mathrm{b}}$ & $13 \pm 2.2^{\mathrm{a}}$ & $7.7 \pm 0.70^{b}$ & $8.4 \pm 2.50^{b}$ & $13 \pm 1.7^{\mathrm{a}}$ & $10 \pm 1.1^{\mathrm{ab}}$ & $8.1 \pm 2.00^{\mathrm{b}}$ \\
\hline $\begin{array}{l}\text { Phenylalanin } \\
\text { e }\end{array}$ & $27 \pm 1.1$ & $24 \pm 1.3$ & $25 \pm 1.8$ & $20 \pm 2.0$ & $25 \pm 4.6$ & $24 \pm 2.7$ & $27 \pm 2.8^{\mathrm{a}}$ & $24 \pm 2.5^{\mathrm{ab}}$ & $21 \pm 2.2^{b}$ \\
\hline Serine & $24 \pm 3.6$ & $25 \pm 4.1$ & $27 \pm 3.1$ & $30 \pm 2.6^{\mathrm{a}}$ & $25 \pm 2.7^{\mathrm{ab}}$ & $23 \pm 2.7^{b}$ & $25 \pm 2.6^{\mathrm{ab}}$ & $26 \pm 3.4^{\mathrm{a}}$ & $20 \pm 3.4^{b}$ \\
\hline Threonine & $48 \pm 5.4$ & $50 \pm 18.8$ & $55 \pm 6.7$ & $43 \pm 5.6$ & $40 \pm 4.6$ & $44 \pm 4.9$ & $59 \pm 5.0^{\mathrm{a}}$ & $39 \pm 5.5^{\mathrm{b}}$ & $52 \pm 6.0^{\mathrm{a}}$ \\
\hline Tyrosine & $37 \pm 3.0^{\mathrm{a}}$ & $22 \pm 4.5^{\mathrm{c}}$ & $28 \pm 2.9^{b}$ & $38 \pm 2.4^{\mathrm{a}}$ & $29 \pm 4.3^{b}$ & $32 \pm 6.8^{\mathrm{ab}}$ & $38 \pm 1.0^{\mathrm{a}}$ & $38 \pm 4.5^{\mathrm{a}}$ & $28 \pm 5.0^{b}$ \\
\hline Valine & $44 \pm 9.1^{\mathrm{a}}$ & $32 \pm 5.5^{b}$ & $35 \pm 2.8^{\mathrm{ab}}$ & $26 \pm 4.31$ & $30 \pm 4.0$ & $27 \pm 2.6$ & $30 \pm 4.9^{\mathrm{ab}}$ & $32 \pm 4.9^{\mathrm{a}}$ & $24 \pm 3.4^{b}$ \\
\hline
\end{tabular}

Data are expressed as means $\pm \mathrm{SEM}, \mathrm{n}=5$. Means with different superscripts in a row differ $(P<0.05) .{ }^{1}$ Including aspartate plus asparagine. ${ }^{2}$ Including glutamate plus glutamine. Sixty Duroc $\times$ Landrace $\times$ Yorkshire piglets weaned at 21 days of age were randomly assigned into 3 treatment groups, representing supplementation with 0 or $1 \mathrm{~g} / \mathrm{kg}$ of the AS extracts, or $0.2 \mathrm{~g} / \mathrm{kg}$ of colistin to maize-soybean-based diets. Blood samples of 5 piglets per group were randomly collected on d 7, 14 and 28 to determine serum contents of free amino acids. Adapted from Kong et al. (50).

Table 6. Apparent ileal digestibilitis (\%) of amino acids in weaned piglets on d 7-28 after initiation of dietary supplementation with Acanthopanax senticosus extracts (ASE)

\begin{tabular}{|c|c|c|c|c|c|c|c|c|c|}
\hline \multirow{3}{*}{ Item } & \multicolumn{9}{|c|}{ Day after initiation of dietary supplementation } \\
\hline & \multicolumn{3}{|c|}{ Day 7} & \multicolumn{3}{|l|}{ Day 14} & \multicolumn{3}{|l|}{ Day 28} \\
\hline & ASE & Colistin & None & ASE & Colistin & None & ASE & Colistin & None \\
\hline Alanine & $69 \pm 6.4$ & $73 \pm 1.2$ & $71 \pm 1.4$ & $82 \pm 4.8^{\mathrm{a}}$ & $77 \pm 3.4^{b}$ & $77 \pm 2.4^{\mathrm{b}}$ & $86 \pm 5.6$ & $82 \pm 3.9$ & $80 \pm 4.0$ \\
\hline Arginine & $84 \pm 3.9^{\mathrm{a}}$ & $65 \pm 1.3^{\mathrm{b}}$ & $64 \pm 2.0^{\mathrm{b}}$ & $87 \pm 7.0^{\mathrm{a}}$ & $83 \pm 2.1^{\mathrm{a}}$ & $76 \pm 2.1^{\mathrm{b}}$ & $76 \pm 12.7$ & $80 \pm 2.1$ & $81 \pm 3.1$ \\
\hline Aspartate $^{1}$ & $72 \pm 7.5$ & $73 \pm 2.0$ & $70 \pm 3.7$ & $84 \pm 3.5^{\mathrm{a}}$ & $81 \pm 3.4^{b}$ & $80 \pm 3.3 b$ & $88 \pm 5.9^{\mathrm{a}}$ & $87 \pm 2.0^{\mathrm{a}}$ & $76 \pm 2.2^{b}$ \\
\hline Cysteine & $74 \pm 3.1^{\mathrm{a}}$ & $65 \pm 2.1^{\mathrm{b}}$ & $62 \pm 2.0^{\mathrm{b}}$ & $86 \pm 9.5^{\mathrm{a}}$ & $76 \pm 3.0^{\mathrm{b}}$ & $74 \pm 3.1^{b}$ & $85 \pm 7.6^{\mathrm{a}}$ & $82 \pm 2.3^{\mathrm{a}}$ & $75 \pm 2.3^{b}$ \\
\hline Glutamate $^{2}$ & $75 \pm 4.6$ & $75 \pm 1.6$ & $73 \pm 1.9$ & $85 \pm 4.4^{\mathrm{a}}$ & $84 \pm 2.5^{\mathrm{a}}$ & $79 \pm 2.4^{b}$ & $94 \pm 6.0^{\mathrm{a}}$ & $89 \pm 3.2^{b}$ & $90 \pm 3.4^{b}$ \\
\hline Glycine & $69 \pm 6.6$ & $71 \pm 2.3$ & $72 \pm 2.4$ & $74 \pm 9.2$ & $80 \pm 3.3$ & $77 \pm 4.4$ & $79 \pm 4.6^{\mathrm{a}}$ & $83 \pm 2.2^{\mathrm{a}}$ & $75 \pm 2.0^{\mathrm{b}}$ \\
\hline Histidine & $74 \pm 5.9^{\mathrm{a}}$ & $65 \pm 1.1^{\mathrm{a}}$ & $60 \pm 1.1^{\mathrm{b}}$ & $85 \pm 10.3^{\mathrm{a}}$ & $78 \pm 2.2^{\mathrm{a}}$ & $70 \pm 2.1^{b}$ & $83 \pm 5.8^{\mathrm{a}}$ & $83 \pm 2.1^{a}$ & $72 \pm 2.0^{b}$ \\
\hline Isoleucine & $72 \pm 3.0^{\mathrm{a}}$ & $70 \pm 1.1^{\mathrm{a}}$ & $65 \pm 1.5^{b}$ & $82 \pm 10.9$ & $81 \pm 3.3$ & $78 \pm 2.4$ & $71 \pm 2.5^{b}$ & $86 \pm 3.1^{a}$ & $84 \pm 4.0^{\mathrm{a}}$ \\
\hline Leucine & $73 \pm 7.5^{b}$ & $79 \pm 2.2^{\mathrm{a}}$ & $70 \pm 3.4^{b}$ & $83 \pm 5.6^{\mathrm{a}}$ & $78 \pm 2.4^{\mathrm{ab}}$ & $76 \pm 2.2^{b}$ & $87 \pm 7.4^{b}$ & $89 \pm 2.4^{a}$ & $82 \pm 2.9^{c}$ \\
\hline Lysine & $72 \pm 7.8^{\mathrm{a}}$ & $67 \pm 2.0^{\mathrm{ab}}$ & $65 \pm 2.3^{b}$ & $84 \pm 7.5^{\mathrm{a}}$ & $74 \pm 3.3^{b}$ & $67 \pm 1.5^{\mathrm{c}}$ & $82 \pm 7.6^{\mathrm{a}}$ & $82 \pm 2.1^{\mathrm{a}}$ & $75 \pm 2.1^{b}$ \\
\hline Methionine & $68 \pm 2.0^{\mathrm{a}}$ & $70 \pm 2.8^{\mathrm{a}}$ & $61 \pm 2.0^{b}$ & $76 \pm 3.3$ & $75 \pm 4.1$ & $74 \pm 3.5$ & $80 \pm 2.2$ & $81 \pm 3.2$ & $82 \pm 2.3$ \\
\hline Phenylalanine & $75 \pm 4.5^{\mathrm{a}}$ & $72 \pm 1.1^{\mathrm{ab}}$ & $70 \pm 0.9^{b}$ & $86 \pm 9.5^{\mathrm{a}}$ & $81 \pm 1.7^{\mathrm{a}}$ & $74 \pm 1.9^{b}$ & $82 \pm 3.9^{\mathrm{a}}$ & $84 \pm 2.3^{\mathrm{a}}$ & $76 \pm 2.4^{b}$ \\
\hline Serine & $69 \pm 3.2$ & $67 \pm 2.9$ & $65 \pm 3.0$ & $84 \pm 12.9^{\mathrm{a}}$ & $79 \pm 2.4^{\mathrm{a}}$ & $75 \pm 2.3^{b}$ & $77 \pm 10.4^{\mathrm{b}}$ & $90 \pm 2.2^{\mathrm{a}}$ & $83 \pm 2.1^{\mathrm{b}}$ \\
\hline Threonine & $63 \pm 3.2^{\mathrm{ab}}$ & $65 \pm 2.0^{\mathrm{a}}$ & $59 \pm 2.3^{b}$ & $79 \pm 5.3$ & $80 \pm 2.3$ & $78 \pm 3.7$ & $73 \pm 7.3^{b}$ & $83 \pm 2.2^{\mathrm{a}}$ & $75 \pm 2.3^{b}$ \\
\hline Tyrosine & $65 \pm 2.2^{\mathrm{ab}}$ & $68 \pm 2.0^{\mathrm{a}}$ & $60 \pm 2.1^{b}$ & $80 \pm 3.1$ & $79 \pm 2.3$ & $81 \pm 2.4$ & $79 \pm 2.3$ & $80 \pm 3.1$ & $77 \pm 3.1$ \\
\hline Valine & $70 \pm 2.0^{\mathrm{a}}$ & $62 \pm 2.1^{b}$ & $64 \pm 2.3^{b}$ & $81 \pm 8.2^{\mathrm{ab}}$ & $84 \pm 3.4^{\mathrm{a}}$ & $78 \pm 2.2^{b}$ & $75 \pm 6.6^{b}$ & $80 \pm 3.2^{\mathrm{a}}$ & $74 \pm 2.3^{b}$ \\
\hline
\end{tabular}

Data are expressed as means \pm SEM, $\mathrm{n}=4$. Means with different superscripts in a row differ $(P<0.05)$. ${ }^{1}$ Including aspartate plus asparagine. ${ }^{2}$ Including glutamate plus glutamine. Twelve barrows with an average initial body weight of $7.64 \mathrm{~kg}$ were also randomly assigned into the 3 dietary treatment groups, representing supplementation with 0 or $1 \mathrm{~g} / \mathrm{kg}$ of the AS extracts, or $0.2 \mathrm{~g} / \mathrm{kg}$ of colistin to maize-soybean-based diets, after surgicallyfitted with a simple T-cannula at the terminal ileum. The samples of terminal ileal digesta were collected on d 7, 14 and 28 for determining apparent ileal digestibilitis of amino acids. Adapted from Kong et al. (50).

Further studies were conducted to determine the effects of AS extracts $(1 \mathrm{~g} / \mathrm{kg})$ as a dietary additive on serum concentrations and AID of AA in piglets weaned at 21 days of age. Collectively, results indicate that the serum concentrations and AID of most AA in the AS extracts-supplemented group were gradually increased by $15.3 \%-80.8 \%$ and $4.1 \%-30.8 \%$, respectively, in comparison with the colistin-additive group and/or control group (Table 5 and 6). These findings suggest that the AS extracts could enhance the ability of digestion and absorption of AA, which may be a potential mechanism of its growth-promoting efficacy (50).
Growth of animals is an outcome of complex metabolic transformations, including AA and glucose utilization, intracellular protein turnover and fat deposition as well as their regulation by hormones and other factors $(11,51-55)$. Consistent with this view, dietary supplementation with the AS extracts enhance the serum concentrations and AID of most AA in 21- to 49-day-old weaned piglets. Therefore, the AS extracts improves the digestion and absorption of dietary protein/AA, and may also directly regulate the metabolism of absorbed nutrients through signal transduction mechanisms $(20,56,57)$. Because the large numbers of components in the Chinese herb make 
Table 7. Serum concentrations $(\mu \mathrm{g} / \mathrm{mL})$ of amino acids in weaned piglets on $\mathrm{d} 7-28$ after initiation of dietary supplementation with Astragalus polysaccharides (APS)

\begin{tabular}{|c|c|c|c|c|c|c|c|c|c|c|c|}
\hline \multirow{3}{*}{ Item } & \multicolumn{9}{|c|}{ Day after initiation of dietary supplementation } & \multirow{3}{*}{ Pooled SEM ${ }^{3}$} & \multirow{3}{*}{$\begin{array}{l}\text { Time effect } \\
\text { P Value }\end{array}$} \\
\hline & \multicolumn{3}{|c|}{ Day 7} & \multicolumn{3}{|c|}{ Day 14} & \multicolumn{3}{|c|}{ Day 28} & & \\
\hline & APS $^{1}$ & Colistin & Control & APS $^{1}$ & Colistin & Control & APS $^{1}$ & Colistin & Control & & \\
\hline \multicolumn{12}{|c|}{ Nutritionally indispensable amino acids } \\
\hline Arginine & $32.5^{\mathrm{c}}$ & $46.6^{\mathrm{a}}$ & $40.1^{\mathrm{b}}$ & $44.4^{\mathrm{a}}$ & $38.5^{\mathrm{b}}$ & $35.1^{\mathrm{b}}$ & $53.4^{\mathrm{a}}$ & $47.5^{\mathrm{b}}$ & $42.0^{\mathrm{c}}$ & 1.4 & $<0.01$ \\
\hline Histidine & $21.3^{\mathrm{b}}$ & $25.7^{\mathrm{a}}$ & $20.5^{\mathrm{b}}$ & $17.5^{\mathrm{a}}$ & $13.0^{\mathrm{b}}$ & $14.2^{\mathrm{b}}$ & $17.9^{\mathrm{a}}$ & $16.1^{\mathrm{b}}$ & $13.2^{\mathrm{c}}$ & 0.64 & $<0.01$ \\
\hline Isoleucine & $18.4^{\mathrm{c}}$ & $23.5^{\mathrm{a}}$ & $19.9^{\mathrm{b}}$ & $23.8^{\mathrm{a}}$ & $21.3^{\mathrm{b}}$ & $18.8^{\mathrm{b}}$ & $18.8^{b}$ & $22.3^{\mathrm{a}}$ & $16.4^{\mathrm{c}}$ & 0.57 & 0.01 \\
\hline Leucine & $34.5^{\mathrm{b}}$ & $40.1^{\mathrm{a}}$ & $37.0^{\mathrm{ab}}$ & $35.5^{\mathrm{a}}$ & $35.2^{\mathrm{a}}$ & $30.3^{\mathrm{b}}$ & $39.7^{\mathrm{a}}$ & $39.3^{\mathrm{a}}$ & $27.3^{\mathrm{b}}$ & 0.88 & $<0.01$ \\
\hline Lysine & $38.4^{\mathrm{c}}$ & $54.4^{\mathrm{a}}$ & $47.8^{\mathrm{b}}$ & $61.2^{\mathrm{a}}$ & $50.5^{\mathrm{b}}$ & $43.5^{\mathrm{c}}$ & $46.4^{\mathrm{b}}$ & $48.5^{\mathrm{a}}$ & $37.6^{\mathrm{c}}$ & 0.99 & $<0.01$ \\
\hline Methionine & $24.1^{\mathrm{c}}$ & $41.0^{\mathrm{a}}$ & $36.0^{\mathrm{b}}$ & $41.1^{\mathrm{a}}$ & $34.4^{\mathrm{b}}$ & $31.7^{\mathrm{b}}$ & $47.4^{\mathrm{a}}$ & $42.5^{\mathrm{b}}$ & $35.5^{\mathrm{c}}$ & 1.2 & $<0.01$ \\
\hline Phenylalanine & $17.4^{b}$ & $24.3^{\mathrm{a}}$ & $24.6^{\mathrm{a}}$ & 25.3 & 24.6 & 24.1 & $23.6^{\mathrm{a}}$ & $23.9^{\mathrm{a}}$ & $20.6^{b}$ & 0.51 & $<0.01$ \\
\hline Threonine & $36.4^{\mathrm{c}}$ & $49.9^{\mathrm{a}}$ & $45.0^{\mathrm{b}}$ & $52.0^{\mathrm{a}}$ & $39.6^{\mathrm{c}}$ & $44.0^{\mathrm{b}}$ & $69.7^{\mathrm{a}}$ & $38.4^{\mathrm{c}}$ & $51.4^{\mathrm{b}}$ & 0.94 & $<0.01$ \\
\hline Proline & $23.0^{\mathrm{c}}$ & $39.3^{\mathrm{a}}$ & $33.6^{b}$ & $38.3^{\mathrm{a}}$ & $34.4^{\mathrm{a}}$ & $29.0^{b}$ & $44.6^{\mathrm{a}}$ & $39.7^{b}$ & $35.3^{\mathrm{c}}$ & 1.4 & \\
\hline Tryptophan & $33.3^{b}$ & $39.8^{\mathrm{a}}$ & $34.0^{\mathrm{b}}$ & $38.4^{\mathrm{a}}$ & $33.0^{\mathrm{b}}$ & $30.6^{\mathrm{b}}$ & $45.4^{\mathrm{a}}$ & $40.5^{b}$ & $36.6^{\mathrm{c}}$ & 0.91 & $<0.01$ \\
\hline Valine & 25.4 & 31.0 & 25.4 & 29.3 & 29.5 & 27.7 & 27.9 & 31.5 & 24.4 & 0.88 & 0.09 \\
\hline \multicolumn{12}{|c|}{ Nutritionally dispensable amino acids } \\
\hline Alanine & $68.1^{\mathrm{b}}$ & $97.9^{\mathrm{a}}$ & $98.6^{\mathrm{a}}$ & $98.6^{\mathrm{a}}$ & $88.2^{\mathrm{b}}$ & $76.7^{\mathrm{b}}$ & $84.4^{\mathrm{b}}$ & $91.1^{\mathrm{a}}$ & $65.2^{\mathrm{c}}$ & 0.68 & $<0.01$ \\
\hline Aspartate $^{1}$ & $6.9^{\mathrm{b}}$ & $9.6^{\mathrm{a}}$ & $6.9^{\mathrm{b}}$ & $11.3^{\mathrm{a}}$ & $8.1^{\mathrm{b}}$ & $7.5^{b}$ & $11.2^{\mathrm{a}}$ & $11.6^{\mathrm{a}}$ & $9.9^{\mathrm{b}}$ & 0.54 & $<0.01$ \\
\hline Cysteine & $3.8^{\mathrm{b}}$ & $3.5^{\mathrm{c}}$ & $5.0^{\mathrm{a}}$ & $6.9^{\mathrm{a}}$ & $4.6^{\mathrm{b}}$ & $3.9^{\mathrm{b}}$ & 3.6 & 3.4 & 3.7 & 0.22 & \\
\hline Glutamate $^{2}$ & $114^{\mathrm{b}}$ & $137^{\mathrm{a}}$ & $116^{\mathrm{b}}$ & $104^{\mathrm{b}}$ & $112^{\mathrm{b}}$ & $76.8^{\mathrm{c}}$ & $119^{\mathrm{b}}$ & $116^{\mathrm{b}}$ & $110^{\mathrm{b}}$ & 3.4 & $<0.01$ \\
\hline Glycine & $99.4^{\mathrm{b}}$ & $110^{\mathrm{a}}$ & $115^{\mathrm{a}}$ & $94.1^{\mathrm{b}}$ & $95.5^{\mathrm{b}}$ & $103^{b}$ & $101^{\mathrm{b}}$ & $120^{\mathrm{a}}$ & $96.5^{\mathrm{b}}$ & 2.6 & $<0.01$ \\
\hline Serine & $23.3^{b}$ & $25.5^{\mathrm{ab}}$ & $26.6^{\mathrm{a}}$ & $27.6^{\mathrm{a}}$ & $25.1^{\mathrm{ab}}$ & $22.9^{b}$ & $21.6^{b}$ & $25.7^{\mathrm{a}}$ & $20.4^{\mathrm{c}}$ & 1.0 & 0.04 \\
\hline Tyrosine & 74.1 & 73.2 & 70.9 & $64.4^{\mathrm{b}}$ & $73.4^{\mathrm{a}}$ & $53.3^{\mathrm{c}}$ & $77.4^{\mathrm{a}}$ & $80.7^{\mathrm{a}}$ & $72.1^{b}$ & 1.1 & $<0.01$ \\
\hline
\end{tabular}

$\mathrm{a}, \mathrm{b}, \mathrm{c}$ Within the same age groups, values in a row sharing different superscript letters differ $(P<0.05) ; \mathrm{n}=5$. ${ }^{1}$ Including aspartate plus asparagine. ${ }^{2}$ Including glutamate plus glutamine. ${ }^{3} \mathrm{SEM}=$ standard error of the mean. Sixty pigs were weaned at 21 days of age and allocated to three treatments, representing supplementing $0.0 \%$ (control), $0.02 \%$ colistin (antibiotic), or $0.1 \%$ APS to a corn- and soybean meal- based diet. Blood samples were obtained from five pigs selected randomly from each treatment for the measurement of serum concentrations of free amino acids on Days 7, 14 and 28. Adapted from Yin et al. (64).

their screening and analysis extremely challenging, our findings help identify the water soluble extracts of the AS as a natural green dietary additive for promoting the healthy growth in weaned piglets.

\section{EFFECTS OF DIETARY SUPPLEMENTATION WITH ASTRAGALUS POLYSACCHARIDE ON ILEAL DIGESTIBILITIES OF AMINO ACIDS IN WEANED PIGLETS}

Some polysaccharide phytochemicals can profoundly affect the immune system (58) and intestinal function $(17,37)$. Such work raised an attractive possibility that these natural substances may be highly effective in ameliorating the problems of weaning-associated gut dysfunction and growth retardation syndrome in pigs. In this regard, it is noteworthy that polysaccharide fractions of Astragalus membranaceus and Astragalus polysaccharide (APS) have been reported to reduce fatigue, the loss of appetite, and the incidence of diarrhea in animals (47, 59-61). Additionally, there is evidence that dietary supplementation with APS can improve growth performance in early-weaned pig (62). To elucidate the underling mechanisms, we conducted a study using APS isolated from AM (37), as previously described (63). Sliced rhizomes of AM grown in Liaoning Province of China were extracted three times with boiling water. The supernatant was applied to a DEAE-Sephacel $(2.6 \times 100$ $\mathrm{cm})$ column, and bound materials were eluted with a linear gradient of 0 to $2 \mathrm{mM} \mathrm{NaCl}$. The fractions containing carbohydrates were pooled and precipitated three times with ethanol. The resultant polysaccharide extract was dialyzed against several changes of water and then lyophilized. The final product contained $95 \%$ carbohydrate but no detectable protein or nuclear acids, as measured at 280 and $260 \mathrm{~nm}$ wavelengths (37). The molecular weight of the extract was approximately $3.5 \times 10^{3}$ to $1.55 \times 10^{6}$, as determined by the gel filtration method.

Testing the hypothesis that dietary APS supplementation may stimulate the digestion of dietary protein and the absorption of resultant $\mathrm{AA}$, therefore improving growth performance in weaned piglets, we determined AID of AA and their serum concentrations in the piglets weaned at 21 days of age after dietary supplementation with APS. We found that addition of APS to the diet increased AID and serum concentrations of most nutritionally essential and nonessential AA (including arginine, proline, glutamate, lysine, methionine, tryptophan, and threonine) on Days 14 and 28. Circulating levels of total AA were affected by the age of pigs and treatment $\times$ time interaction (Table 7 and 8). These findings indicate that APS may ameliorate the digestive and absorptive function and regulate AA metabolism to beneficially increase the entry of dietary AA into the systemic circulation, which provide a mechanism to explain the growth-promoting effect of APS in weaned piglets (64).

Although AID of threonine and valine on Day 14 or AID of leucine, isoleucine, methionine, and phenylalanine on Day 28 did not differ between APS-supplemented pigs and the control group, serum concentrations of these essential AA were higher in APS-supplemented pigs. Because these AA cannot be synthesized in enterocytes or extra-intestinal cells of pigs (31) but can be extensively degraded by intestinal luminal bacteria (65), an increase in their serum concentrations in APS-treated pigs may result from a reduction in their 
Table 7. Serum concentrations $(\mu \mathrm{g} / \mathrm{mL})$ of amino acids in weaned piglets on $\mathrm{d} 7-28$ after initiation of dietary supplementation with Astragalus polysaccharides (APS)

\begin{tabular}{|c|c|c|c|c|c|c|c|c|c|c|c|}
\hline \multirow{3}{*}{ Item } & \multicolumn{9}{|c|}{ Day after initiation of dietary supplementation } & \multirow{3}{*}{ Pooled SEM $^{3}$} & \multirow{3}{*}{$\begin{array}{l}\text { Time effect } \\
\text { P Value }\end{array}$} \\
\hline & \multicolumn{3}{|c|}{ Day 7} & \multicolumn{3}{|c|}{ Day 14} & \multicolumn{3}{|c|}{ Day 28} & & \\
\hline & $\mathbf{A P S}^{1}$ & Colistin & Control & $\mathbf{A P S}^{1}$ & Colistin & Control & $\mathbf{A P S}^{1}$ & Colistin & Control & & \\
\hline \multicolumn{12}{|c|}{ Nutritionally indispensable amino acids } \\
\hline Arginine & $32.5^{\mathrm{c}}$ & $46.6^{\mathrm{a}}$ & $40.1^{\mathrm{b}}$ & $44.4^{\mathrm{a}}$ & $38.5^{\mathrm{b}}$ & $35.1^{\mathrm{b}}$ & $53.4^{\mathrm{a}}$ & $47.5^{\mathrm{b}}$ & $42.0^{\mathrm{c}}$ & 1.4 & $<0.01$ \\
\hline Histidine & $21.3^{\mathrm{b}}$ & $25.7^{\mathrm{a}}$ & $20.5^{\mathrm{b}}$ & $17.5^{\mathrm{a}}$ & $13.0^{\mathrm{b}}$ & $14.2^{\mathrm{b}}$ & $17.9^{\mathrm{a}}$ & $16.1^{\mathrm{b}}$ & $13.2^{\mathrm{c}}$ & 0.64 & $<0.01$ \\
\hline Isoleucine & $18.4^{\mathrm{c}}$ & $23.5^{\mathrm{a}}$ & $19.9^{\mathrm{b}}$ & $23.8^{\mathrm{a}}$ & $21.3^{\mathrm{b}}$ & $18.8^{\mathrm{b}}$ & $18.8^{\mathrm{b}}$ & $22.3^{\mathrm{a}}$ & $16.4^{\mathrm{c}}$ & 0.57 & 0.01 \\
\hline Leucine & $34.5^{\mathrm{b}}$ & $40.1^{\mathrm{a}}$ & $37.0^{\mathrm{ab}}$ & $35.5^{\mathrm{a}}$ & $35.2^{\mathrm{a}}$ & $30.3^{\mathrm{b}}$ & $39.7^{\mathrm{a}}$ & $39.3^{\mathrm{a}}$ & $27.3^{\mathrm{b}}$ & 0.88 & $<0.01$ \\
\hline Lysine & $38.4^{\mathrm{c}}$ & $54.4^{\mathrm{a}}$ & $47.8^{\mathrm{b}}$ & $61.2^{\mathrm{a}}$ & $50.5^{\mathrm{b}}$ & $43.5^{\mathrm{c}}$ & $46.4^{b}$ & $48.5^{\mathrm{a}}$ & $37.6^{\mathrm{c}}$ & 0.99 & $<0.01$ \\
\hline Methionine & $24.1^{\mathrm{c}}$ & $41.0^{\mathrm{a}}$ & $36.0^{\mathrm{b}}$ & $41.1^{\mathrm{a}}$ & $34.4^{\mathrm{b}}$ & $31.7^{\mathrm{b}}$ & $47.4^{\mathrm{a}}$ & $42.5^{\mathrm{b}}$ & $35.5^{\mathrm{c}}$ & 1.2 & $<0.01$ \\
\hline Phenylalanine & $17.4^{b}$ & $24.3^{\mathrm{a}}$ & $24.6^{\mathrm{a}}$ & 25.3 & 24.6 & 24.1 & $23.6^{\mathrm{a}}$ & $23.9^{\mathrm{a}}$ & $20.6^{b}$ & 0.51 & $<0.01$ \\
\hline Threonine & $36.4^{\mathrm{c}}$ & $49.9^{\mathrm{a}}$ & $45.0^{\mathrm{b}}$ & $52.0^{\mathrm{a}}$ & $39.6^{\mathrm{c}}$ & $44.0^{\mathrm{b}}$ & $69.7^{\mathrm{a}}$ & $38.4^{\mathrm{c}}$ & $51.4^{\mathrm{b}}$ & 0.94 & $<0.01$ \\
\hline Proline & $23.0^{\mathrm{c}}$ & $39.3^{\mathrm{a}}$ & $33.6^{\mathrm{b}}$ & $38.3^{\mathrm{a}}$ & $34.4^{\mathrm{a}}$ & $29.0^{\mathrm{b}}$ & $44.6^{\mathrm{a}}$ & $39.7^{b}$ & $35.3^{\mathrm{c}}$ & 1.4 & \\
\hline Tryptophan & $33.3^{\mathrm{b}}$ & $39.8^{\mathrm{a}}$ & $34.0^{6}$ & $38.4^{\mathrm{a}}$ & $33.0^{\mathrm{b}}$ & $30.6^{b}$ & $45.4^{\mathrm{a}}$ & $40.5^{b}$ & $36.6^{\mathrm{c}}$ & 0.91 & $<0.01$ \\
\hline Valine & 25.4 & 31.0 & 25.4 & 29.3 & 29.5 & 27.7 & 27.9 & 31.5 & 24.4 & 0.88 & 0.09 \\
\hline \multicolumn{12}{|c|}{ Nutritionally dispensable amino acids } \\
\hline Alanine & $68.1^{\mathrm{b}}$ & $97.9^{\mathrm{a}}$ & $98.6^{\mathrm{a}}$ & $98.6^{\mathrm{a}}$ & $88.2^{\mathrm{b}}$ & $76.7^{b}$ & $84.4^{\mathrm{b}}$ & $91.1^{\mathrm{a}}$ & $65.2^{\mathrm{c}}$ & 0.68 & $<0.01$ \\
\hline Aspartate $^{1}$ & $6.9^{\mathrm{b}}$ & $9.6^{\mathrm{a}}$ & $6.9^{\mathrm{b}}$ & $11.3^{\mathrm{a}}$ & $8.1^{\mathrm{b}}$ & $7.5^{b}$ & $11.2^{\mathrm{a}}$ & $11.6^{\mathrm{a}}$ & $9.9^{b}$ & 0.54 & $<0.01$ \\
\hline Cysteine & $3.8^{\mathrm{b}}$ & $3.5^{\mathrm{c}}$ & $5.0^{\mathrm{a}}$ & $6.9^{\mathrm{a}}$ & $4.6^{\mathrm{b}}$ & $3.9^{\mathrm{b}}$ & 3.6 & 3.4 & 3.7 & 0.22 & \\
\hline Glutamate $^{2}$ & $114^{\mathrm{b}}$ & $137^{\mathrm{a}}$ & $116^{\mathrm{b}}$ & $104^{b}$ & $112^{\mathrm{b}}$ & $76.8^{\mathrm{c}}$ & $119^{b}$ & $116^{b}$ & $110^{\mathrm{b}}$ & 3.4 & $<0.01$ \\
\hline Glycine & $99.4^{\mathrm{b}}$ & $110^{\mathrm{a}}$ & $115^{\mathrm{a}}$ & $94.1^{\mathrm{b}}$ & $95.5^{\mathrm{b}}$ & $103^{\mathrm{b}}$ & $101^{\mathrm{b}}$ & $120^{\mathrm{a}}$ & $96.5^{\mathrm{b}}$ & 2.6 & $<0.01$ \\
\hline Serine & $23.3^{\mathrm{b}}$ & $25.5^{\mathrm{ab}}$ & $26.6^{\mathrm{a}}$ & $27.6^{\mathrm{a}}$ & $25.1^{\mathrm{ab}}$ & $22.9^{\mathrm{b}}$ & $21.6^{\mathrm{b}}$ & $25.7^{\mathrm{a}}$ & $20.4^{\mathrm{c}}$ & 1.0 & 0.04 \\
\hline Tyrosine & 74.1 & 73.2 & 70.9 & $64.4^{\mathrm{b}}$ & $73.4^{\mathrm{a}}$ & $53.3^{\mathrm{c}}$ & $77.4^{\mathrm{a}}$ & $80.7^{\mathrm{a}}$ & $72.1^{b}$ & 1.1 & $<0.01$ \\
\hline
\end{tabular}

$\overline{\mathrm{a}, \mathrm{b}, \mathrm{c}}$ Within the same age groups, values in a row sharing different superscript letters differ $(P<0.05) ; \mathrm{n}=5$. ${ }^{1}$ Including aspartate plus asparagine. ${ }^{2}$ Including glutamate plus glutamine. ${ }^{3} \mathrm{SEM}=$ standard error of the mean. Sixty pigs were weaned at 21 days of age and allocated to three treatments, representing supplementing $0.0 \%$ (control), $0.02 \%$ colistin (antibiotic), or $0.1 \%$ APS to a corn- and soybean meal- based diet. Blood samples were obtained from five pigs selected randomly from each treatment for the measurement of serum concentrations of free amino acids on Days 7, 14 and 28. Adapted from Yin et al. (64).

Table 8. Apparent ileal digestibilitis ( ) of amino acids in weaned piglets on d 7-28 after initiation of dietary supplementation with Astragalus polysaccharides (APS)

\begin{tabular}{|c|c|c|c|c|c|c|c|c|c|c|c|}
\hline \multirow{3}{*}{ Item } & \multicolumn{9}{|l|}{ Time } & \multirow{3}{*}{ Pooled SEM ${ }^{2}$} & \multirow{3}{*}{$\begin{array}{l}\text { Time effec } \\
\text { P Value }\end{array}$} \\
\hline & \multicolumn{3}{|l|}{ d 7} & \multicolumn{3}{|l|}{ d 14} & \multicolumn{3}{|l|}{ d 28 } & & \\
\hline & $\mathbf{A P S}^{1}$ & Colistin & Control & $\mathbf{A P S}^{1}$ & Colistin & Control & $\mathbf{A P S}^{1}$ & Colistin & Control & & \\
\hline \multicolumn{12}{|c|}{ Nutritionally indispensable amino acids } \\
\hline Arginine & 88.2 & 89.7 & 84.7 & 89.3 & 87.4 & 83.4 & 86.5 & 87.6 & 83.3 & 0.87 & 0.07 \\
\hline Histidine & $83.0^{\mathrm{a}}$ & $83.6^{\mathrm{a}}$ & $80.2^{\mathrm{b}}$ & $75.6^{\mathrm{a}}$ & $74.3^{\mathrm{a}}$ & $71.5^{\mathrm{b}}$ & $82.4^{\mathrm{a}}$ & $82.5^{\mathrm{a}}$ & $74.4^{\mathrm{b}}$ & 0.84 & $<0.01$ \\
\hline Isoleucine & 76.3 & 76.7 & 75.4 & $75.4^{\mathrm{a}}$ & $71.4^{\mathrm{b}}$ & $66.5^{\mathrm{c}}$ & 77.3 & 79.6 & 77.5 & 0.90 & $<0.01$ \\
\hline Leucine & $83.4^{\mathrm{a}}$ & $83.0^{\mathrm{a}}$ & $80.5^{\mathrm{b}}$ & $73.4^{\mathrm{a}}$ & $71.7^{\mathrm{ab}}$ & $68.3^{\mathrm{b}}$ & 79.5 & 82.5 & 81.2 & 0.99 & $<0.01$ \\
\hline Lysine & $77.2^{\mathrm{b}}$ & $79.5^{\mathrm{a}}$ & $79.3^{\mathrm{a}}$ & $74.7^{\mathrm{a}}$ & $73.6^{\mathrm{a}}$ & $68.5^{\mathrm{b}}$ & $77.5^{\mathrm{a}}$ & $78.7^{\mathrm{a}}$ & $73.7^{\mathrm{b}}$ & 0.92 & $<0.01$ \\
\hline Methionine & $74.4^{\mathrm{a}}$ & $75.4^{\mathrm{a}}$ & $69.6^{b}$ & $76.6^{\mathrm{a}}$ & $75.2^{\mathrm{a}}$ & $63.4^{b}$ & 75.4 & 74.3 & 76.1 & 1.0 & $<0.01$ \\
\hline Phenylalanine & $78.3^{\mathrm{a}}$ & $76.3^{\mathrm{a}}$ & $73.7^{\mathrm{b}}$ & $71.6^{\mathrm{a}}$ & $72.3^{\mathrm{a}}$ & $69.3^{\mathrm{b}}$ & 77.5 & 78.5 & 80.6 & 1.2 & $<0.01$ \\
\hline Proline & 75.6 & 76.6 & 74.8 & $76.3^{\mathrm{a}}$ & $78.5^{\mathrm{a}}$ & $72.6^{\mathrm{b}}$ & 73.4 & 70.7 & 69.5 & 1.1 & \\
\hline Threonine & 76.5 & 77.5 & 75.5 & $60.4^{\mathrm{b}}$ & $66.6^{\mathrm{a}}$ & $60.6^{\mathrm{b}}$ & $73.4^{\mathrm{a}}$ & $73.5^{\mathrm{a}}$ & $70.4^{\mathrm{b}}$ & 0.99 & $<0.01$ \\
\hline Tryptophan & $71.7^{\mathrm{a}}$ & $70.7^{\mathrm{a}}$ & $66.7^{\mathrm{b}}$ & $81.4^{\mathrm{a}}$ & $83.5^{\mathrm{a}}$ & $73.4^{b}$ & $70.4^{\mathrm{a}}$ & $71.7^{\mathrm{a}}$ & $62.1^{\mathrm{b}}$ & 0.98 & $<0.01$ \\
\hline Tyrosine & 74.1 & 73.2 & 70.9 & $64.4^{b}$ & $73.4^{\mathrm{a}}$ & $53.3^{\mathrm{c}}$ & $77.4^{\mathrm{a}}$ & $80.7^{\mathrm{a}}$ & $72.1^{\mathrm{b}}$ & 1.1 & $<0.01$ \\
\hline Valine & $81.1^{\mathrm{a}}$ & $77.0^{\mathrm{b}}$ & $78.4^{\mathrm{ab}}$ & $68.5^{\mathrm{b}}$ & $74.0^{\mathrm{a}}$ & $67.3^{\mathrm{b}}$ & $77.6^{\mathrm{a}}$ & $78.5^{\mathrm{a}}$ & $74.4^{\mathrm{b}}$ & 0.91 & $<0.01$ \\
\hline \multicolumn{12}{|c|}{ Nutritionally dispensable amino acids } \\
\hline Alanine & 74.6 & 74.6 & 72.6 & $68.8^{\mathrm{a}}$ & $67.2^{\mathrm{a}}$ & $64.2^{\mathrm{b}}$ & $75.5^{\mathrm{b}}$ & $78.3^{\mathrm{a}}$ & $76.5^{\text {ab }}$ & 0.77 & $<0.01$ \\
\hline Aspartate $^{1}$ & 75.6 & 74.1 & 76.6 & 70.6 & 72.5 & 69.2 & $79.4^{\mathrm{a}}$ & $77.8^{\mathrm{ab}}$ & $74.5^{\mathrm{b}}$ & 1.1 & $<0.01$ \\
\hline Glutamate $^{2}$ & $54.4^{\mathrm{a}}$ & $48.9^{\mathrm{b}}$ & $43.3^{\mathrm{c}}$ & $72.6^{\mathrm{a}}$ & $70.6^{\mathrm{ab}}$ & $67.2^{\mathrm{b}}$ & $76.3^{\mathrm{a}}$ & $70.6^{\mathrm{c}}$ & $73.3^{\mathrm{b}}$ & 1.2 & $<0.01$ \\
\hline Cysteine & $72.3^{b}$ & $76.6^{\mathrm{a}}$ & $70.7^{b}$ & $68.7^{\mathrm{a}}$ & $69.4^{\mathrm{a}}$ & $66.1^{b}$ & $76.2^{b}$ & $82.2^{\mathrm{a}}$ & $79.4^{\mathrm{C}}$ & 0.92 & \\
\hline Glycine & $68.7^{\mathrm{a}}$ & $68.4^{\mathrm{a}}$ & $60.6^{\mathrm{b}}$ & $72.4^{\mathrm{a}}$ & $67.2^{\mathrm{b}}$ & $68.3^{b}$ & $72.5^{\mathrm{a}}$ & $70.3^{\mathrm{a}}$ & $58.3^{\mathrm{b}}$ & 0.99 & 0.02 \\
\hline Serine & 67.3 & 68.3 & 67.6 & $72.1^{a}$ & $74.6^{\mathrm{a}}$ & $66.5^{\mathrm{b}}$ & $80.1^{\mathrm{a}}$ & $80.8^{\mathrm{a}}$ & $69.5^{\mathrm{b}}$ & 1.2 & $<0.01$ \\
\hline Tyrosine & $24.3 a$ & $22.1 \mathrm{~b}$ & $21.8 \mathrm{~b}$ & $35.6^{\mathrm{a}}$ & $29.5^{\mathrm{b}}$ & $30.9^{\mathrm{b}}$ & $33.7^{\mathrm{b}}$ & $37.9^{\mathrm{a}}$ & $27.6^{\mathrm{c}}$ & 0.84 & $<0.01$ \\
\hline
\end{tabular}

${ }_{\mathrm{a}, \mathrm{b}, \mathrm{c}}$ Within the same age groups, values in a row sharing different superscript letters differ $(P<0.05) ; \mathrm{n}=5 .{ }^{1}$ Including aspartate plus asparagine. ${ }^{2}$ Including glutamate plus glutamine. ${ }^{3} \mathrm{SEM}=$ standard error of the mean. Twelve pigs were weaned at 21 day of age (body weight $=7.64 \pm 0.71 \mathrm{~kg}$ ), assigned to three treatment group, representing supplementing $0.0 \%$ (control), $0.02 \%$ colistin (antibiotic), or $0.1 \%$ APS to a corn- and soybean meal-based diet, and surgically fitted with a simple T-cannula at the terminal ileum. Ileal digesta samples were obtained on d 7, 14 and 28 for determining apparent ileal digestibilitis of amino acids. Adapted from Yin et al. (64).

atabolism by the gut microorganisms. This raised a possibility that APS may beneficially modulate the number, population, and activity of intestinal microbes to favor the entry of dietary AA into the portal circulation. We suggest that this phytochemical may be an effective, as well as a useful alternative of antibiotics in swine production. On this basis, APS can be classified as a prebiotic to replace antibiotics in swine diets. 
Table 9. Plasma concentrations ( $\mu \mathrm{mol} / \mathrm{L})$ of the arginine family of amino acids in weaned piglets after initiation of dietary supplementation with glycyrrhetinic acid (GA)

\begin{tabular}{|l|l|l|l|l|l|}
\hline \multirow{2}{*}{ Amino acid } & Day 9 & Day 14 & Day 21 \\
\cline { 2 - 7 } & Control & GA & Control & GA & Control \\
\hline Arginine & $70 \pm 10.3$ & $74 \pm 12.2$ & $51 \pm 7.3$ & $56 \pm 9.0$ & $42 \pm 3.9$ \\
\hline Proline & $93 \pm 10.3$ & $104 \pm 11.5$ & $143 \pm 13.5$ & $135 \pm 17.4$ & $86 \pm 2.9$ \\
\hline Glutamate $^{1}$ & $252 \pm 31.2$ & $235 \pm 24.8$ & $403 \pm 34.1$ & $434 \pm 55.8$ & $94 \pm 3.8^{*}$ \\
\hline
\end{tabular}

* Means differ from the control group $(P<0.05) .{ }^{1}$ Including glutamate plus glutamine. $\mathrm{n}=8$. Landrace $\times$ Yorkshire male pigs at 7 day of age were weaned to a milk-replacing powder (MRP) diet. After a 2-d adaptation period, thirty pigs were randomly assigned to one of 2 groups on the basis of body weight and litter (15 pigs per group). The MRP was supplemented with or without $200 \mathrm{mg}$ GA/kg diet for 12 days. At 9, 14, and 21 days of age, the jugular-vein blood samples were obtained randomly from 8 pigs per group for analysis of free amino acids in plasma. Adapted from Yin et al. (73).

Table 10. Arginase activity and polyamine synthesis from arginine in jejunal enterocytes of postweaning pigs receiving BIOPOWDER (BP) supplementation

\begin{tabular}{|l|l|l|l|}
\hline Measured Variable & $\mathbf{0 ~ p p m ~ B P}$ & $\mathbf{1 2 0} \mathbf{~ p p m ~ B P}$ & $\mathbf{1 8 0} \mathbf{~ p p m ~ B P}$ \\
\hline Arginase activity, nmol/mg protein per min & $2.16 \pm 0.11^{\mathrm{c}}$ & $2.68 \pm 0.14^{\mathrm{b}}$ & $3.15 \pm 0.17^{\mathrm{a}}$ \\
\hline ODC activity, pmol/mg protein per h & $96.1 \pm 3.4^{\mathrm{c}}$ & $119.4 \pm 6.2^{\mathrm{b}}$ & $143.7 \pm 6.8^{\mathrm{a}}$ \\
\hline Synthesis of polyamines, pmol/mg protein per 45 min & $42.5 \pm 2.7^{\mathrm{c}}$ & $57.3 \pm 3.5^{\mathrm{b}}$ & $70.4 \pm 4.3^{\mathrm{a}}$ \\
\hline
\end{tabular}

Data are means \pm SEM, $n=8$. Landrace $\times$ Yorkshire male pigs were weaned at 21 days of age to a corn- and soybean meal-based diet (72). The basal diet was supplemented with 0,120 or 180 ppm BIOPOWDER (BP). At 30 days of age, pigs were euthanized to obtain jejunal enterocytes (72). Arginase activity, ornithine decarboxylase (ODC) activity, and synthesis of polyamines (putrescine plus spermidine plus spermine) from arginine in cells were determined as previously described (72). Results were analyzed using one-way analysis of variance and the Student-Newman-Keuls multiple comparison. a-c: Means sharing different superscript letters within a row differ $(P<0.05)$.

\section{EFFECTS OF DIETARY SUPPLEMENTATION WITH GLYCYRRHETINIC ACID ON ENDOGENOUS ARGININE PROVISION IN EARLY-WEANED PIGLETS}

Radix Glycyrrhizae, the root or root plus the rhizome of legume such as Glycyrrhiza uralensis Fisch., Glycyrrhiza inflat Bat. and Glycyrrhiza glabra L., is thought to possess the effects of invigorating spleen, replenishing $q i$ (vigor), eliminating phlegm, arresting cough, clearing away heat and toxins, relieving spasm and pain, and moderating the properties of other drugs and so on (66). Modern pharmacological studies reveal that glycyrrhetinic acid (GA) is a major constituent of licorice and has many therapeutic properties, including anti-inflammatory, anti-ulcer, anti-allergic, anti-viral, hepaprotective, anti-tumor, and immumodulatory actions (67). Interestingly, some herbal extracts contain GA (a pentacyclic triterpenoid derivative of the $\hat{\mathrm{I}}^{2}$-type amyrin), which has a chemical structure similar to cortisol (Figure 1). Therefore, GA inhibits the activity of 11-beta- hydroxysteroid dehydrogenase type 2, enhances the function of cortisol, and is often used clinically as a substitute for cortisol (68). Of particular note, cortisol has recently been reported to enhance the synthesis of arginine (an essential AA for neonates), generation of polyamines (key regulators of DNA and protein synthesis), and intestinal growth in neonatal pigs (69-71).

Based on the above findings, we designed one experiment to investigate the effects of GA on the earlyweaned piglets fed with milk-replacing diet, as well as the effects of GA on the endocrine, plasma concentrations of the arginine family of amino acids (including arginine, praline and glutamate), activity of ornithine decarboxylase (ODC) in small intestine mucosa of piglets. Our data showed that dietary supplementation with $0.02 \%$ GA increased arginine concentration in plasma (Table 9) and the activity of ODC in the pig jejunum on day 21 (Figure 2), as previously reported for suckling piglets receiving intramuscular administration of cortisol (6) and weanling piglets with a natural surge of cortisol (72). The GA treatment did not affect circulating levels of cortisol, growth hormone, or insulin $(P>0.05)$, when compared with the control group. Small-intestinal villus height and daily weight gain were $30 \%$ and $21 \%$ higher, respectively, in pigs treated with $0.02 \%$ GA than in the control pigs on day 21. These findings indicate that $0.02 \% \mathrm{GA}$ increases endogenous arginine provision and intestinal ODC expression, improves small-intestinal morphology, and enhances growth performance in young pigs (73).

\section{EFFECTS OF STEROIDAL SAPONIN FROM YUCCA SCHIDIGERA EXTRACT (BIOPOWDER) ON INTESTINAL ARGINASE ACTIVITY}

The Yucca schidigera plant is endemic of the southwest desert in the United States and the north part of Baja California in Mexico (74). The Yucca schidigera extract (BIOPOWDER) is generally recognized as a safe (GRAS) product and approved by the U.S. Food and Drug Administration (FDA) as a natural food adjuvant under Title 21CFR 172.510. This unique substance is also fed to livestock species (including swine) and poultry to improve air quality (e.g., reductions in ammonia levels and odors) in production barns, health, and productivity parameters (75-77). Thus, BIOPOWDER is widely used in animal nutrition. Of particular interest, Yucca schidigera extract consists of steroidal derivatives (74), which may modulate intestinal remodeling as physiological glucocorticoids do [e.g., cortisol (69-72)]. We have previously reported that administration of cortisol to sow-reared piglets increases intestinal arginase expression to promote the conversion of arginine into polyamines (71), which are substances essential for DNA and protein synthesis (13). Notably, similar results were obtained for intestinal arginase and ODC activities in postweaning pigs receiving dietary supplementation of 120 and $180 \mathrm{ppm}$ BIOPOWDER (Table 10). Thus, Yucca schidigera extract 


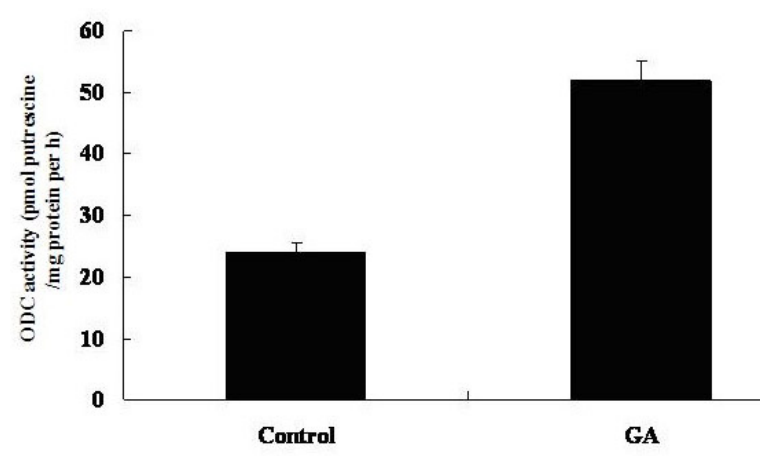

Figure 1. Molecular structure of glycyrrhetinic acid (A) and cortisol (B).

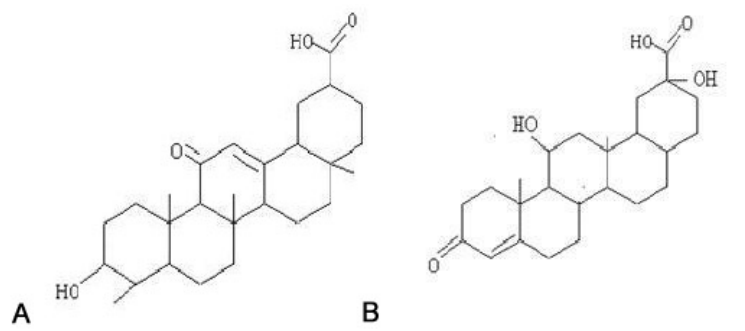

Figure 2. Effect of glycyrrhetinic acid (GA) on ornithine decarboxylase (ODC) activity in jejunal enterocytes of weaned piglets. Values are means \pm SEM, $n=6$. ODC activity in the GA group was greater $(\mathrm{P}<0.05)$ than that in the control group. Landrace $\times$ Yorkshire male pigs at $7 \mathrm{~d}$ of age were weaned and fed a milk-replacing powder (MRP) diet and water. After a 2-d period of adaptation, 12 pigs were randomly assigned to one of two groups on the basis of body weight and litter (6 pigs per group). The MRP was supplemented with or without $200 \mathrm{mg} \mathrm{GA} / \mathrm{kg}$ diet for $12 \mathrm{~d}$. At $21 \mathrm{~d}$ of age, pigs were euthanized and ODC activity in jejunal enterocytes was determined, as described by Wu et al. (71). Adapted from Yin et al. (73).

can stimulate arginine degradation for polyamine synthesis in pig enterocytes (Table 10), as demonstrated for cortisol (69-72). The nutritional and physiological significance of this novel finding remains to be determined.

\section{SUMMARY AND PERSPECTIVE}

Composition of AA in CHM is not unique among ingredients of plant origin. Bioactive substances in CHM act through mechanisms involving multiple systems and cells, including the small intestine, muscle, and lymphoid organs. Thus, studies with animal models demonstrate that dietary supplementation with $\mathrm{CHM}$ phytochemicals enhances the AID and absorption of dietary AA, as well as growth and health. Because the underlying mechanisms are likely to be complex and multifactorial, future studies are warranted to determine the effects of active components of CHM phytochemicals on digestion of dietary nutrients, gene expression, cell signaling, and metabolism. Achievement of these long-term goals can be greatly facilitated using omics techniques (e.g., genomics, proteomics, and metabolomics) (78-80) and bioinformatics (81). Such new knowledge will aid in full understanding of how CHM ingredients regulate physiological processes in organisms. Results obtained from animal studies will also have important implications for human nutrition and health.

\section{ACKNOWLEDGEMENTS}

This research was jointly supported by grants from NSFC (30901040, 30928018), an ISA Young Scholar Project (ISACX-LYQY-QN-0703), K.C. Wang Education Foundation of Hong Kong, National 863 project (2008AA10Z316), GungDong and Chinese Academy Cooperative projects (2009B091300043, 2009B091300079, 2009B091300089), the Outstanding Overseas Chinese Scholars Fund of the Chinese Academy of Sciences (2005-1-4), the Thousand-People-Talent program at China Agricultural University, and the Texas AgriLife Research Hatch project (H-8200).

\section{REFERENCES}

1. Cheng JT: Review: Drug therapy in Chinese traditional medicine. J Clin Pharmacol 40, 445-450 (2000)

2. Wang Mei, Robert-Jan AN Lamers, Henrie AAJ Korthout, Joop HJ van Nesselrooij, Renger F Witkamp, Rob van der Heijden, Peter J Voshol, Louis M Havekes, Rob Verpoorte and Jan van der Greef: Metabolomics in the Context of Systems Biology: Bridging Traditional Chinese Medicine and Molecular Pharmacology. Phytother Res 19, 173-182 (2005)

3. Paul Chan and Brian Tomlinson: Antioxidant Effects of Chinese Traditional Medicine: Focus on Trilinolein Isolated from the Chinese Herb Sanchi (Panax pseudoginseng). $J$ Clin Pharmacol 40, 457-461 (2000)

4. Kong Xiang-feng, Guo-yao Wu, Yu-long Yin, Mei-juan Bo, Bi-e Tan, Feng Yang, Tie-jun Li, Rui-lin Huang, Fu-gui Yin and Fu-yong Yan: Role of Chinese herbal medicine in livestock nutrition and health. Recent Progress in Medicinal Plants (Muti-Volume Series), Vol. 24 (2008)

5. Elango R, RO Ball and PB Pencharz: Amino acid requirements in humans: with a special emphasis on the metabolic availability of amino acids. Amino Acids 37, 19-27 (2009)

6. Flynn NE, JG Bird and AS Guthrie: Glucocorticoid regulation of amino acid and polyamine metabolism in the small intestine. Amino Acids 37, 123-129 (2009)

7. Haynes TE, Peng Li, Xi-long Li, K Shimotori, H Sato, NE Flynn, Jun-jun Wang, DA Knabe and Guo-yao Wu: L-Glutamine or L-alanyl-L-glutamine prevents oxidant- or endotoxin-induced death of neonatal enterocytes. Amino Acids 37, 131-142 (2009)

8. Kim Sung Woo and Guo-yao Wu: Regulatory role for amino acids in mammary gland growth and milk synthesis. Amino Acids 37, 89-95 (2009) 
9. Wang Wei-wei, Si-yan Qiao and De-fa Li: Amino acids and gut function. Amino Acids 37, 105-110 (2009)

10. Baker DH: Advances in protein-amino acid nutrition of poultry. Amino Acids 37, 29-41 (2009)

11. Li Xi-long, FW Bazer, Hai-jun Gao,Wen-juan Jobgen, GA Johnson, Peng Li, JR Mcknight, MC Satterfield, TE Spencer and Guo-yao Wu: Amino acids and gaseous signaling. Amino Acids 37, 65-78 (2009)

12. Palii SS, CE Kays, C Deval, A Bruhat, P Fafournoux and MS Kilberg: Specificity of amino acid regulated gene expression: analysis of gene subjected to either complete or single amino acid deprivation. Amino Acids 37, 79-88 (2009)

13. Wu Guo-yao: Amino acids: metabolism, functions, and nutrition. Amino Acids 37, 1-17 (2009)

14. Rhoads JM and Guo-yao Wu: Glutamine, arginine, and leucine signaling in the intestine. Amino Acids 37, 111-122 (2009)

15. Wu Xin, Xiang-feng Kong, Yu-long Yin, Fu-gui Yin, Ping Zhang, He-jun Liu, Fang-fang Xing, Qing-hua He, Tie-jun Li, Rui-lin Huang and Guo-yao Wu: Composition of amino acids in typical Chinese herbs is not unique among feeds of plant origin. J Anim Sci 85 (Suppl. 1), 252 (2007)

16. Kong Xiang-feng, Guo-yao Wu, Yi-ping Liao, Zhen-ping. Hou, He-jun Liu, Fu-gui Yin, Tie-jun Li, Rui-lin Huang, You-ming Zhang, Dun Deng, Ping Kang, R.X. Wang, Zhi-ru Tang, Cheng-bo Yang, Zhe-yuan Deng, Hua Xiong, Wu-ying Chu, Zheng Ruan, Ming-yong Xie and Yu-long Yin: Effects of Chinese herbal ultra-fine powder as a dietary additive on growth performance, serum metabolites and intestinal health in early-weaned piglets. Livest Sci 108, 272-275 (2007)

17. Kong Xiang-feng, Guo-yao Wu, Yi-ping Liao, Zhen-ping. Hou, He-jun Liu, Fu-gui Yin, Tie-jun Li, Rui-lin Huang, You-ming Zhang, Dun Deng, Ming-yong Xie, Zhe-yuan Deng, Hua Xiong, Zheng Ruan, Ping Kang, Cheng-bo Yang, Yu-long Yin and Ming-zhe Fan: Dietary supplementation with Chinese herbal ultra-fine powder enhances cellular and humoral immunity in early-weaned piglets. Livest Sci 108, 94-98 (2007)

18. He Qing-hua, Xiang-feng Kong, Yong-qing Hou, Yu-long Yin, Fu-gui Yin, He-jun Liu, Tie-jun Li, Rui-lin Huang, Hai Yu and Jian-hua Gong: Effects of Chinese herbal ultra-fine powder as a dietary additive on gut microflora in early-weaned piglets. In: Recent Progress in Medicinal Plants (Muti-Volume Series), Studium Press, LLC, USA, Houston, Texas, 24: 453-465 (2008)

19. Hu C.-A A, S Khalil, S Zhaorigetu, Z Liu, M Tyler, G Wan and D Valle: Human $\Delta^{1}$-pyrroline-5-carboxylate synthase: function and regulation. Amino Acids 35, 665-672 (2008)
20. Jobgen Wenjuan Shi, Susan K Fried, Wen-jian J Fu, Cynthia J Meininger and Guo-yao Wu: Regulatory role for the arginine-nitric oxide pathway in metabolism of energy substrate. J Nutr Biochem 17, 571-588 (2006)

21. Phang JM, SP Donald, J Pandhare and Y Liu: The metabolism of proline, as a stress substrate, modulates carcinogenic pathways. Amino Acids 35, 681-690 (2008)

22. Stipanuk MH, I Ueki, JE Dominy Jr, CR Simmons and LL Hirschberger: Cysteine dioxygenase: a robust system for regulation of cellular cysteine levels. Amino Acids 37, 55-63 (2009)

23. Li Peng, Yu-long Yin, De-fa Li, SW Kim and Guo-yao $\mathrm{Wu}$ : Amino acids and immune function. Br J Nutr 98, 237-252 (2007)

24. Kong Xiang-feng, Yu-long Yin, Qing-hua He, Fu-gui Yin, He-jun Liu, Tie-jun Li, Rui-lin Huang, Mei-mei Geng, Zheng Ruan, Zhe-yuan Deng, Ming-yong Xie and Guo-yao Wu: Dietary supplementation with Chinese herbal powder enhances ileal digestibilities and serum concentrations of amino acids in young pigs. Amino acids 37, 573-582 (2009)

25. Jobgen Wenjuan Shi, Wen-jiang J. Fu, Hai-jun Gao, Peng Li, CJ Meininger, SB Smith, TE Spencer and Guo-yao Wu: High fat feeding and dietary L-arginine supplementation differentially regulate gene expression in rat white adipose tissue. Amino Acids 37, 187-198 (2009)

26. Ma Xian-yong, Ying-cai Lin, Zong-yong Jiang, Chun-tian Zheng, Gui-lian Zhou, De-qian Yu, Ting Cao, Jun Wang and Fang Chen: Dietary arginine supplementation enhances antioxidative capacity and improves meat quality of finishing pigs. Amino Acids 38, 95-102 (2010)

27. Wu Guo-yao, Yun-zhong Fang, Sheng Yang, JR Lupton and ND Turner: Glutathione metabolism and its implications for health. $J$ Nutr 134, 489-492 (2004)

28. Wu Guo-yao, FW Bazer, TA Davis, LA Jaeger, GA Johnson, SW Kim, DA Knabe, CJ Meininger, TE Spencer and Yu-long Yin: Important roles for the arginine family of amino acids in swine nutrition and production. Livest Sci $112,8-22$ (2007)

29. Dai Zhao-lai, Jing Zhang, Guo-yao Wu and Wei-yun Zhu: Utilization of amino acids by bacteria from the pig small intestine. Amino Acids. doi: 10.1007/s00726-010-0556-9

30. Yang Fang, Jun-jun Wang, Xiao-jie Li, Tian-yi Ying, Shi-yan Qiao, De-fa Li and Guo-yao Wu: Two-dimensional gel electrophoresis and mass spectrometry analysis of interactions between Lactobacillus Fermentum I5007 and intestinal epithelial cells. Electrophoresis 28, 4330-4339 (2007)

31. Wu Guo-yao: Intestinal mucosal amino acid catabolism. J Nutr 128, 1249-1252 (1998) 
32. Yin Yu-long, Rui-lin Huang, Tie-jun Li, Zheng Ruan, Ming-yong Xie, Zhe-yuan Deng, Yong-qing Hou and Guo-yao Wu: Amino acid metabolism in the portal-drained viscera of young pigs: effects of dietary supplementation with chitosan and pea hull. Amino Acids. DOI: 10.1007/s00726-010-0577-4

33. Fuller Malcolm F and Peter J Redes: Nitrogen cycling in the gut. Annu Rev Nutr 18, 385-411 (1998)

34. Yi Jin-Mu, Seung-Heon Hong, Jong-Ha Kim, Hyeong-Kyun Kim, Ho-Joon Song and Hyung-Min Kim: Effect of Acanthopanax senticosus stem on mast cell-dependent anaphylaxis. J Ethnopharm 79, 347-352 (2002)

35. Fujikawa Takahiko, Akihiko Yamaguchi, Isao Morita, Hidekatsu Takeda and Sansei Nishibe: Protective effects of Acanthopanax senticosus harms from Hokkaido and its components on gastric ulcer in restrained cold water stressed rats. Biol Pharmaceut Bull 19, 1227-1230 (1996)

36. Jung HJ, HJ Park, RG Kim, KM Shin, J Ha, JW Choi, HJ Kim, YS Lee and KT Lee: In vivo anti-inflammatory and anti-nociceptive effects of liriodendrin isolated from the stem bar of Acanthopanax senticosus. Planta Med 69, 610-616 (2003)

37. Kong Xiang-feng, Yu-long Yin, Guo-yao Wu, He-jun Liu, Fu-gui Yin, Tie-jun Li, Rui-lin Huang, Zheng Ruan, Hua Xiong, Zhe-yuan Deng, Ming-yong Xie, Yi-ping Liao and Sung Woo Kim: Dietary supplementation with the Acanthopanax senticosus extract enhances cellular and humoral immunities in early-weaned piglets. Asian-Aust $J$ Anim Sci 20, 1453-1461 (2007)

38. Yin Fu-gui, Yu-long Yin, Xiang-feng Kong, He-jun Liu, Cheng-bo Yang, Guo-yao Wu, Qing-hua He, Tie-jun Li and Rui-lin Huang: Dietary supplementation with Acanthopanax senticosus extract modulates gut microflora in weaned piglet. Asian-Aust J Anim Sci 21, 1330-1338 (2008)

39. Cho William Chi Shing and Kwok Nam Leung: In vitro and in vivo immunomodulating and immunorestorative effects of Astragalus membranaceus. J Ethnopharma 113, 132-141 (2007)

40. Wang ZT, TB Ng, HW Yeung and GJ Xu: Immunomodulatory effect of a polysaccharide-enriched preparation of Codonopsis pilosula roots. Gen Pharm: Vas Sys 27, 1347-1350 (1996)

41. Kao ErlShyh, ChauJong Wang, WeaLung Lin, ChiaYih Chu and TsuiHwa Tseng: Effects of polyphenols derived from fruit of Crataegus pinnatifida on cell transformation, dermal edema and skin tumor formation by phorbol ester application. Food Chem Toxicol 45, 1795-1804 (2007)

42. Kathrin Dittmann, Clarissa Gerhäuser, Karin Klimo and Matthias Hamburger: HPLC-based activity profiling of salvia miltiorrhiza for MAO A and iNOS inhibitory activities. Planta Med 70, 909-913 (2004)

43. Yin Yu-long, Zhi-ru Tang, Zhi-hong Sun, Zhi-qiang Liu, Tie-jun Li, Rui-lin Huang, Zheng Ruan, Zhe-yuan Deng, Bi Gao, Li-xiang Chen, Guo-yao $\mathrm{Wu}$ and Sung Woo Kim: Effect of galacto-mannan-oligosaccharides or chitosan supplementation on cytoimmunity and humoral immunity response in early-weaned piglets. Asian-Aust J Anim Sci 21, 723-731 (2008)

44. Yang CH, G Liu, CX Zhang and YL Zheng: Progress of study on Acanthopanax. Panax Res 1, 17-21 (2004)

45. Han SB, YD Yoon, HJ Ahn, HS Lee, CW Lee, WK Yoon, SK Park and HM Kim: Toll-like receptormediated activation of $\mathrm{B}$ cells and macrophages by polysaccharide isolated from cell culture of Acanthopanax senticosus. Int Immunopharm 3, 1301-1312 (2003)

46. Nishibe S, H Kinoshita, H Takeda and G Okano: Phenolic compounds from stem bark of Acanthopanax senticosus and their pharmacological effect in chronic swimming stressed rats. Chem Pharm Bull 38, 1763-1765 (1990)

47. Kong Xiang-feng, Yuan-liang Hu, Rong Rui, De-yun Wang and Xiang-rui Li: Effects of Chinese herbal medicinal ingredients on peripheral lymphocyte proliferation and serum antibody titer after vaccination in chicken. Int Immunopharm 4, 975-982 (2004)

48. Chai Shao-fang, Hai-yan Jiang and Yan-ping Ou: Study on organic acid content in different processed products of fructus crataegi. Chin Trad Pat Med 22, 841-842 (2000)

49. Huang Rui-lin, Zhi-liang Tan, Ting-xian Xing, Ya-fei Pan and Tie-jun Li: An in vitro method for the estimation of ileal crude protein and amino acids digestibility using the dialysis tubing for pig feedstuffs. Anim Feed Sci Tech 88, 79-89 (2000)

50. Kong Xiang-feng, Fu-gui Yin, Qing-hua He, He-jun Liu, Tie-jun Li, Rui-lin Huang, Ming-zhe Fan, Yu-lan Liu, Yong-qing Hou, Peng Li, Zheng Ruan, Zhe-yuan Deng, Ming-yong Xie, Hua Xiong and Yu-long Yin: Acanthopanax senticosus extracts as a dietary additive enhances the apparent ileal digestibilities of amino acids in weaned piglets. Livest Sci, 123, 261-267 (2009)

51. Chen Li-xiang, Peng Li, Jun-jun Wang, Xi-long Li, Hai-jun Gao, Yu-long Yin, Yong-qing Hou and Guo-yao Wu: Catabolism of nutritionally essential amino acids in developing porcine enterocytes. Amino Acids 37, 143-152 (2009)

52. Li Peng, Kang-sen Mai, Jrushenshi Trushenski and Guo-yao Wu: New developments in fish amino acid nutrition: towards functional and environmentally oriented aquafeeds. Amino Acids 37, 43-53 (2009)

53. Stoll B and DG Burrin: Measuring splanchnic amino acid metabolism in vivo using stable isotopic tracers. $J$ Anim 
Sci 84, E60-E72 (2006)

54. Suryawan A, PMJ O'Connor, JA Bush, HV Nguyen and TA Davis: Differential regulation of protein synthesis by amino acids and insulin in peripheral and visceral tissues of neonatal pigs. Amino Acids 37, 97-104 (2009)

55. Tan Bi-e, Xin-guo Li, Xiang-feng Kong, Rui-lin Huang, Zheng Ruan, Kang Yao, Ze-yuan Deng, Ming-yong Xie, I Shinzato, Yu-long Yin and Guo-yao Wu: Dietary L-arginine supplementation enhances the immune status in early-weaned piglets. Amino Acids 37, 323-331 (2009)

56. Tan Bi-e, Yu-long Yin, Zhi-qiang Liu, Xin-guo Li, Hai-jun Xu, Xiang-feng Kong, Rui-lin Huang, Wen-jie Tang, I Shinzato, SB Smith and Guo-yao Wu: Dietary L-arginine supplementation increases muscle gain and reduces body fat mass in growing-finishing pigs. Amino Acids 37, 169-175 (2009)

57. Tan Bi-e, Yu-long Yin, Xiang-feng Kong, Peng Li, Xi-long Li, Hai-jun Gao, Xin-guo Li, Rui-lin Huang and Guo-yao Wu: L-Arginine stimulates proliferation and prevents endotoxin-induced death of intestinal cells. Amino Acids 38, 1227-1235 (2010)

58. Lee KY and YJ Jeon: Macrophage activation by polysaccharide isolated from Astragalus membranaceus. Int Immunopharm 5, 1225-1233 (2005)

59. Bedir E, N Pugh, I Calis, DS Pasco and IA Khan: Immunostimulatory effects of cycloartane-type triterpene glycosides from astragalus species. Biol Pharm Bull 23, 834-837 (2000)

60. Cui Ru-tao, Jin-chun He, Bao-en Wang, Fu-kui Zhang, Guang-yong Chen, Shan-shan Yin and Hong Shen: Suppressive effect of Astragalus membranaceus Bunge on chemical hepatocarcinogenesis in rats. Can Chemother Pharma 51, 75-80 (2003)

61. Kong Xiang-feng, Yuan-liang $\mathrm{Hu}$, Yu-long Yin, Guo-yao Wu, Rong Rui, De-yun Wang and Cheng-bo Yang: Chinese herbal ingredients are effective immune stimulators for Chickens infected with the Newcastle disease virus. Poult Sci 85, 2169-2175 (2006)

62. Li Tong-zhou, Wei-ge Hou, Shu-min Zang, Hong Chen and Ling-feng Xue: Effect of Astragalus polysaccharide on growth performance in weanling piglets. China feed 12, 36-38 (2007)

63. Shao BM, W Xu, H Dai, PF Tu, ZJ Li and XM Gao: A study on the immune receptors for polysaccharides from the roots of Astragalus membranaceus, a Chinese medicinal herb. Biochem Biophys Res Commun 320, 1103-1111 (2004)

64. Yin Fu-gui, Yu-lan Liu, Yu-long Yin, Xiang-feng Kong, Rui-lin Huang, Tie-jun Li, Guo-yao Wu and Yong-qing Hou: Dietary supplementation with Astragalus polysaccharide enhances ileal digestibilities and serum concentrations of amino acids in early weaned piglets. Amino Acids 37, 263-270 (2009)

65. Chen Li-Xiang, Yu-Long Yin, WS Jobgen, SC Jobgen, $\mathrm{DA}$ Knabe, Wei-Xin $\mathrm{Hu}$ and Guo-Yao $\mathrm{Wu}$ : In vitro oxidation of essential amino acids by jejunal mucosal cells of growing pigs. Livest Sci 109, 19-23 (2007)

66. Liu CX and PG Xiao: Gancao. An Interoduction to Chinese Materia Medica. Beijing: Beijing Medical University and Peking Union Medical University Press, 166 (1993)

67. Latif SA, TJ Conca and DJ Morris: The effects of the licorice derivative, glycyrrhetinic acid, on hepatic 3 alphaand 3 beta-hydroxysteroid dehydrogenases and 5 alpha- and 5 beta-reductase pathways of metabolism of aldosterone in male rats. Steroids 55, 52-58 (1990)

68. Xiao PG and CX Liu: Pharmacology, pharmacokinetics, toxicology, and therapeutics of traditional Chinese medicines: Radix Glyeyrrhizae. Asian J Drug Metabolism pharmacokinetics 1: 140-150 (2001)

69. Flynn NE and Guo-yao Wu: Glucocorticoids play an important role in mediating the enhanced metabolism of arginine and glutamine in enterocytes of postweaning pigs. J Nutr 127, 732-737 (1997)

70. Flynn NE, CJ Meininger, K Kelly, NH Ing, SM Morris $\mathrm{Jr}$ and Guo-yao Wu: Glucocorticoids mediate the enhanced expression of intestinal type II arginase and argininosuccinate lyase in postweaning pigs. $J$ Nutr 129 , 799-803 (1999)

71. Wu Guo-yao, NE Flynn and DA Knabe: Enhanced intestinal synthesis of polyamines from proline in cortisol-treated piglets. Am J Physiol Endocrinol Metab 279:E395-E402 (2000)

72. Wu Guo-yao, NE Flynn, DA Knabe and LA Jaeger: A cortisol surge mediates the enhanced polyamine synthesis in porcine enterocytes during weaning. Am J Physiol Regul Integr Comp Physiol 279:R554-R559 (2000)

73. Yin Yu-long, Zhi-sang He, Xiang-feng Kong, Rong-qing Hou and Guo-yao Wu: Dietary supplementation with glycyrrhetinic acid (GA) increases endogenous arginine provision, ornithine decarboxylase activity, development of the jejunum and growth performance in milk-fed piglets. FASEB J 22, 705.2 (2008)

74. Piacente S, Pizza C and Oleszek W: Saponins and phenolics of Yucca schidigera Roezl: Chemistry and bioactivity. Phytochem Rev 4, 177-190 (2005)

75. Colina JJ, Lewis AJ, Miller PS and Fischer RL: Dietary manipulation to reduce aerial ammonia concentrations in nursery pig facilities. J Anim Sci 79, 3096-3103 (2001)

76. Cheeke PR: Actual and potential applications of Yucca schidigera and Quillaja saponaria saponins in human and 
Phytochemicals and amino acids

animal nutrition. Proceedings of the Phytochemical Society of Europe 45, 241-254 (2000)

77. Yen JT and Pond WG: Effects of Carbadox, copper, or Yucca shidigera extract on growth performance and visceral weight of young pigs. J Anim Sci 71, 2140-2146 (1993)

78. He Qing-hua, Xiang-feng Kong, Guo-yao Wu, Ping-ping Ren, Hui-ru Tang, Fu-hua Hao, Rui-lin Huang, Tie-jun Li, Bi-e Tan, Peng Li, Zhi-ru Tang, Yu-long Yin and Yong-ning Wu: Metabolomic analysis of the response of growing pigs to dietary L-arginine supplementation. Amino Acids 37, 199-208 (2009)

79. Wang Jun-jun, Guo-yao Wu, Huai-jun Zhou and Feng-lai Wang: Emerging technologies for amino acid nutrition research in the post-genome era. Amino Acids 37, 177-186 (2009)

80. Wang Xiu-qi, De-yuan Ou, Jing-dong Yin, Guo-yao Wu and Jun-jun Wang: Proteomic analysis reveals altered expression of proteins related to glutathione metabolism and apoptosis in the small intestine of zinc oxide-supplemented piglets. Amino Acids 37, 209-218 (2009)

81. Fu WJ, AJ Stromberg, Kert Viele, RJ Carroll and Guo-yao Wu: Statistics and bioinformatics in nutritional sciences: analysis of complex data in the era of systems biology. J Nutr Biochem 21, 561-572 (2010)

Abbreviations: AA, amino acids; AID, apparent ileal digestibilities; AM, Astragalus membranaceus; APS, Astragalus polysaccharide; AS, Acanthopanax senticosus; CHM, Chinese herbal medicine; COP, Codonopsis pilosula; CRP, Crataegus pinnatifida; CTVM, Chinese traditional veterinary medicine; DM, dry matter; GA, Glycyrrhetinic Acid; HPLC, high-pressure liquid chromatography; ODC, ornithine decarboxylase; SM, Salvia miltiorrhiza; UCH, ultra-fine Chinese herbal

Key Words: Chinese herbal medicine, Amino acids, Nutrition, Pigs, Review

Send correspondence to: Yulong Yin, Hunan Engineering and Research Center of Animal and Poultry Science and Key Laboratory for Agro-ecological Processes in Subtropical Region, Institute of Subtropical Agriculture, the Chinese Academy of Sciences, Changsha, Hunan, China 410125, Tel: 86-731-84619703, Fax: 86-731-84612685, E-mail: yinyulong@isa.ac.cn

http://www.bioscience.org/current/volS3.htm 